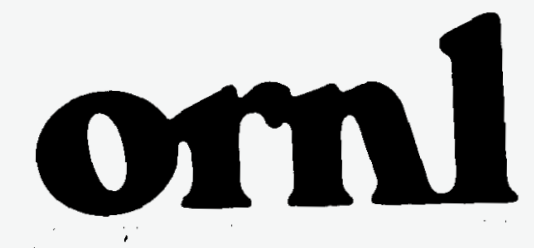

$r$

\section{OAK RIDGE \\ NATIONAL \\ LABORATORY}

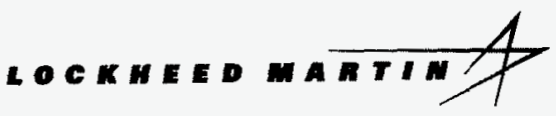

\title{
Potential Effects of Gallium on Cladding Materials
}

\author{
Dane F. Wilson \\ Edward C. Beahm \\ Theodore M. Besmann \\ Jackson H. DeVan \\ James R. DiStefano \\ Uri Gat \\ Sherrell R. Greene \\ Phillip L. Rittenhouse \\ Brian A. Worley
}


This report has been reproduced directly from the best available copy.

Available to DOE and DOE contractors from the Office of Scientific and Technical Information, P. O. Box 62, Oak Ridge, TN 37831; prices available from (423) 576-8401.

Available to the public from the National Technical Information Service, U.S. Department of Commerce, 5285 Port Royal Rd., Springfield, VA 22161.

This report was prepared as an account of work sponsored by an agency of the United States Government. Neither the United States Government nor any agency thereof, nor any of their employees, makes any warranty, express or implied, or assumes any legal liability or responsibility for the accuracy, completeness, or usefulness of any information, appratus, product, or process disclosed, or represents that its use would not infringe privately owned rights. Reference herein to any specific commercial product, process, or service by trade name, trademark, manufacturer, or otherwise, does not necessarily constitute or imply its endorsement, recommendation, or favoring by the United States Government or any agency thereof. The views and opinions of authors expressed herein do not necessarily state or reflect those of the United States Government or any agency thereof. 


\title{
Potential Effects of Gallium on Cladding Materials
}

\author{
Dane. F. Wilson \\ Edward C. Beahm \\ Theodore M. Besmann \\ Jackson H. DeVan \\ James R. DiStefano \\ Uri Gat \\ Sherrell R. Greene \\ Philip L. Rittenhouse \\ Brian A. Worley
}

Date Published: October 1997

NOTICE: This document contains information of a preliminary nature.

It is subject to revision or correction and therefore does not represent a final report.

Prepared for the

U.S, Department of Energy

Office of Fissile Materials Disposition

GA 0102014

Prepared by the

OAK RIDGE NATIONAL LABORATORY

Oak Ridge, Tennessee 37831-6285

managed by

LOCKHEED MARTIN ENERGY RESEARCH

for the

U.S. DEPARTMENT OF ENERGY

under contract DE-AC05-96OR22464 


\section{CONTENTS}

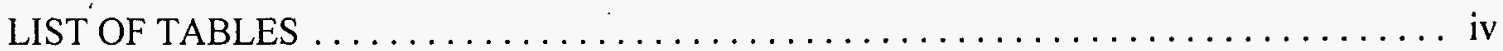

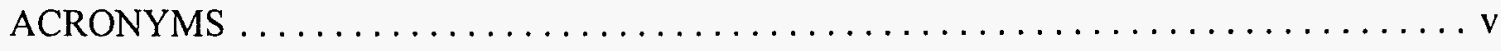

EXECUTIVE SUMMARY $\ldots \ldots \ldots \ldots \ldots \ldots \ldots \ldots \ldots \ldots \ldots \ldots \ldots \ldots \ldots \ldots \ldots$

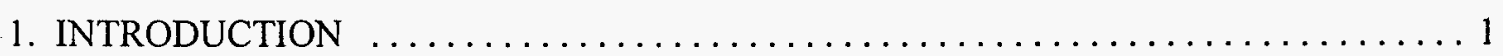

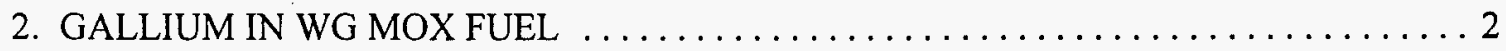

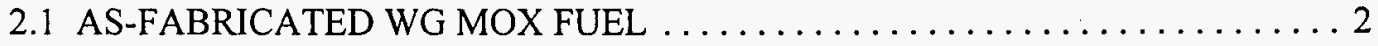

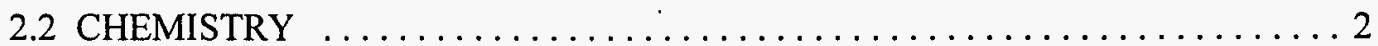

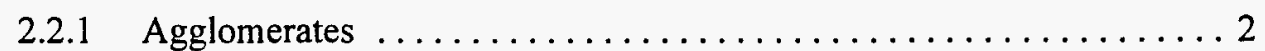

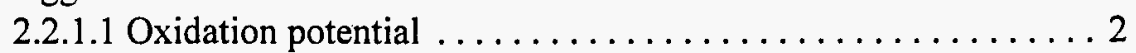

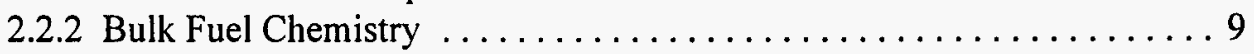

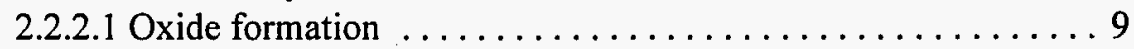

2.2 .3 Reactions with Fission Products $\ldots \ldots \ldots \ldots \ldots \ldots \ldots \ldots \ldots \ldots$

2.3 GALLIUM TRANSPORT MECHANISMS WITHIN FUEL $\ldots \ldots \ldots \ldots \ldots \ldots$

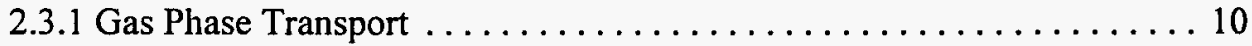

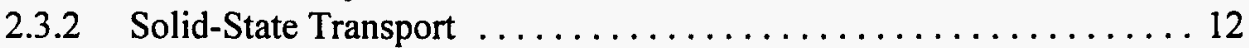

3. CLAD PERFORMANCE AND DEGRADATION MECHANISMS $\ldots \ldots \ldots \ldots \ldots \ldots$

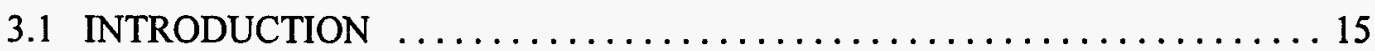

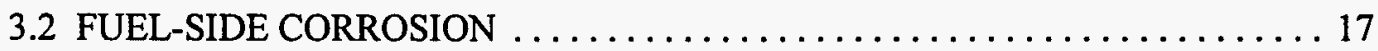

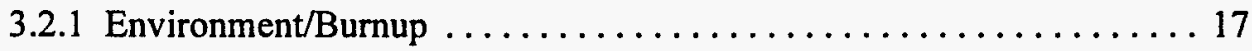

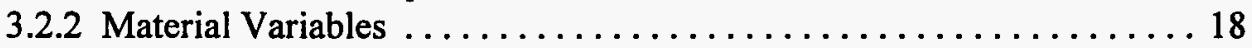

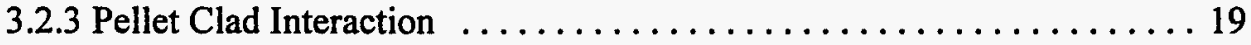

3.2.4 Mechanisms of Gallium Embrittlement ............... 19

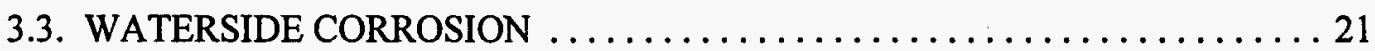

4. GALLIUM AND FUEL PERFORMANCE: CONCLUSIONS AND RECOMMENDATIONS

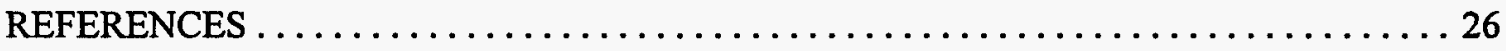

APPENDIX

PHYSICAL, CHEMICAL AND NUCLEAR CHARACTERISTICS OF GALLIUM AND

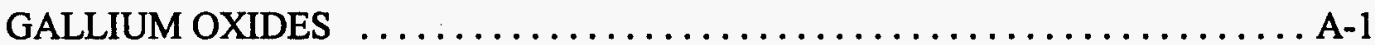

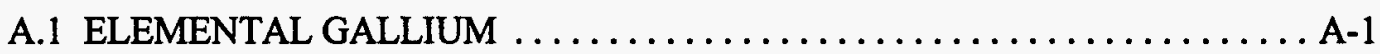

A.1.1 PHYSICAL CHARACTERISTICS $\ldots \ldots \ldots \ldots \ldots \ldots \ldots \ldots \ldots$ A 1

A.1.2 CHEMICAL CHARACTERISTICS $\ldots \ldots \ldots \ldots \ldots \ldots \ldots \ldots$ A-2

A.1.3 NUCLEAR CHARACTERISTICS OF GALLIUM ........... A-3

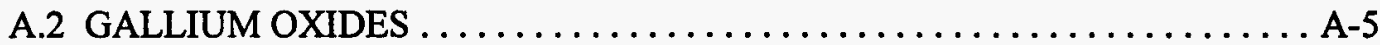

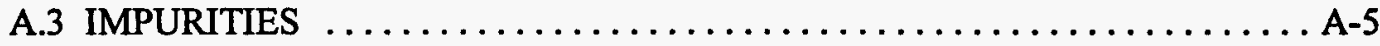

A.3.1 HALOGEN IMPURITIES $\ldots \ldots \ldots \ldots \ldots \ldots \ldots \ldots \ldots \ldots \ldots \ldots$ A -5

A.3.2 CHALCOGENIDE IMPURITIES ................. A-6

A.3.3 REACTIONS WITH GROUP V ELEMENTS . . . . . . . . A A-6

A.4 REFERENCES $\ldots \ldots \ldots \ldots \ldots \ldots \ldots \ldots \ldots \ldots \ldots \ldots \ldots \ldots \ldots \ldots \ldots \ldots \ldots \ldots \ldots \ldots \ldots$ 


\section{LIST OF TABLES}

Table 1. Fission product concentrations computed for a burnup of $52.5 \mathrm{MWd} / \mathrm{kg}$ and their oxidation state assuming gallium is present as the oxide in as-fabricated fuel $\ldots \ldots \ldots \ldots \ldots 6$

Table 2. Fission product concentrations computed for a burnup of $52.5 \mathrm{MWd} / \mathrm{kg}$ and their oxidation state assuming gallium is present unoxidized in as-fabricated fuel $\ldots \ldots \ldots \ldots \ldots 7$

Table 3. Thermodynamic values at $1000 \mathrm{~K}$ for the gallium-oxygen system $\ldots \ldots \ldots \ldots \ldots 11$

Table A.1. Physical properties of gallium $\ldots \ldots \ldots \ldots \ldots \ldots \ldots \ldots \ldots \ldots \ldots \ldots \ldots \ldots \ldots \ldots$

Table A.2. Gallium compounds with zirconium or plutonium $\ldots \ldots \ldots \ldots \ldots \ldots \ldots$ A-2

Table A.3. Chemical properties of gallium $\ldots \ldots \ldots \ldots \ldots \ldots \ldots \ldots \ldots \ldots \ldots \ldots \ldots \ldots \ldots$ 


\section{ACRONYMS}

BWR boiling-water reactor

HE hydrogen embrittlement

ISCC intergranular stress corrosion cracking

LANL Los Alamos National Laboratory

LME liquid metal embrittlement

LWR light-water reactor

MOX mixed oxide

O/M oxygen-to-metal

PCI pellet-clad interaction

PWR pressurized-water reactor

R\&D research and development

SCC stress corrosion cracking

SMIE solid metal-induced embrittlement

WG weapons grade 


\section{EXECUTIVE SUMMARY}

The Department of Energy has announced that the United States will pursue a dual-track approach to the disposition of plutonium arising from the dismantling of nuclear weapons. The dual-track disposition approach involves both immobilization and reactor-based mixed oxide (MOX) fuel technologies. The use of the MOX fuel option requires the assessment of the potential impact of gallium (on the order of $10 \mathrm{ppm}$ ), not present in conventional MOX fuel, on cladding material performance.

This paper identifies and examines issues concerning the incorporation of gallium in weapons-derived plutonium in light water reactor (LWR) MOX fuels. Particular attention is given to the more likely effects of the gallium on the behavior of the cladding material. The chemistry of weapons-grade (WG) MOX, including possible consequences of gallium within plutonium agglomerates, was assessed. Based on the calculated oxidation potentials of MOX fuel, the effect that gallium may have on reactions involving fission products and possible impact on cladding performance were postulated. Gallium transport mechanisms are discussed. With an understanding of oxidation potentials and assumptions of mechanisms for gallium transport, possible effects of gallium on corrosion of cladding were evaluated. Potential and unresolved issues and suggested research and development (R\&D) required to provide missing information are presented.

This analysis concludes that without control of the stoichiometry of the MOX fuel it is possible for the gallium to be present as either elemental gallium or gallium sesquioxide $\left(\mathrm{Ga}_{2} \mathrm{O}_{3}\right)$ in the as-fabricated fuel. To keep gallium as a metal oxide in the as-fabricated fuel, the fuel oxygen-to-metal ratio (O/M) should be at least equal to 2 . During burnup, in an isolated plutonia aggregate the fission products molybdenum, technetium, cadmium, tin, antimony, tellurium, and some ruthenium are computed to be present as oxides.

At temperatures approaching $>1200 \mathrm{~K}$, the vapor pressure of gaseous gallium oxide $\left(\mathrm{Ga}_{2} \mathrm{O}\right)$ will be of the order of $10^{4}$ to $10^{5} \mathrm{~Pa}$. Within the fuel rod, the oxide species may vaporize in significant quantities in the hotter regions and transport to the cooler clad surfaces, where it would condense. Should this mode of mass transfer be particularly effective, reduction of the $\mathrm{Ga}_{2} \mathrm{O}_{3}$ by the zirconium in the clad could have detrimental effects on clad performance. However, significant burnup could serve to reduce this mode of mass transport.

General corrosion of the cladding with gallium or gallium oxide is not a concern. General corrosion is mass limited, and the mass of gallium present in the fuel volume is low relative to the clad volume. However, localized corrosion (grain boundary penetration) and 
liquid-metal embrittlement by gallium are possible compatibility issues that need further investigation. The possibility that gallium will influence water (aqueous) corrosion is considered remote. 


\section{INTRODUCTION}

The Department of Energy announced in January 1997 that the United States will pursue a dual-track surplus plutonium disposition approach in which both immobilization and reactorbased mixed oxide (MOX) fuel technologies will be employed.

Currently, more than a dozen commercial light-water reactors (LWRs) in Europe use recycled plutonium in MOX fuel assemblies. More than 300,000 LWR MOX fuel rods have been irradiated during the past decade. The performance of this commercial LWR MOX fuel has proven to be satisfactory. However, the U.S. weapons-grade (WG) plutonium differs from the commercial recycled reactor-grade plutonium used in Europe in that the WG plutonium contains small quantities (up to 1 mass \%) of gallium, an active material that readily reacts with most metallic materials. Processes used in the fabrication of the MOX fuel could reduce the gallium content to $\sim 10 \mathrm{ppm}$.

The fission product yield of gallium is exceedingly small, therefore, it is present in irradiated LWR uranium dioxide $\left(\mathrm{UO}_{2}\right)$ and commercial MOX fuels at concentrations several orders of magnitude lower than the anticipated levels in MOX fuel containing WG plutonium. Thus, there is no commercial experience with LWR MOX fuels containing gallium at concentrations similar to those expected to result from the use of WG plutonium.

This report identifies and evaluates issues relating to gallium in LWR MOX fuels, particularly as to possible impacts on cladding materials. Because the form of gallium in the fuel could be of importance to its transport and corrosivity, the chemistry of gallium in MOX fuel is the first issue that is considered. The most likely forms of gallium in freshly fabricated WG MOX fuel are identified, and the effects of in-reactor irradiation and thermochemical environments on the physical and chemical forms of gallium are discussed. Likewise, it is important to know whether gallium, in whatever form, can be transported from its location in MOX to the cladding interface such that corrosion reactions are possible. Therefore, potential mechanisms for gallium transport in the fuel pellet are discussed next. Known and postulated cladding mechanisms are then reviewed, and the potential effect of gallium on cladding performance is presented. Finally, potential unresolved issues are presented, and the type of research and development (R\&D) required to provide missing information is suggested.

This assessment is based on data and information available in early 1997 and will be updated as new information evolves from ongoing R\&D programs at Los Alamos National Laboratory (LANL) and Oak Ridge National Laboratory. 


\section{GALLIUM IN WG MOX FUEL}

\subsection{AS-FABRICATED WG MOX FUEL}

Little to no information has been published or is otherwise available for MOX fuel that contains gallium in quantities expected from manufacture using WG plutonium. Therefore, no comparative information for gallium-containing MOX vs conventional MOX is available. This lack of information, especially for newly fabricated fuels, results in the need for confirmation of the inferences at many of the boundary conditions assumed in this report. At the $1 \%$ gallium level in plutonium, a typical MOX fuel assembly would contain $210 \mathrm{~g}$ of gallium. This compares with $5 \mathrm{~g}$ of gallium in a fuel assembly that contains $10 \mathrm{ppm}$ gallium (reduction occurs during fabrication), or $10 \mathrm{mg}$ of gallium because of fission product yield when no initial gallium is present in an assembly.

\subsection{CHEMISTRY}

The chemistry of gallium in MOX fuel may be influenced by its distribution. This section considers two possibilities: (1) a second phase agglomerate of plutonium dioxide $\left(\mathrm{PuO}_{2}\right)$ containing $\mathrm{Ga}$, and (2) $\mathrm{Ga}$ uniformly distributed either as an individual phase or in a solution of $(\mathrm{U}, \mathrm{Pu}) \mathrm{O}_{2}$.

\subsubsection{Agglomerates}

Depending on the MOX fuel preparation process, the plutonium (and gallium) may be present as second-phase agglomerates within the larger volume of $\mathrm{UO}_{2}$. The implications of this assumption are considered in this section.

\subsubsection{Oxidation potential}

It is important to know the state of the gallium (elemental or oxide) that may be present with plutonium as $\mathrm{PuO}_{2}$. Currently, no gallium-oxygen phase diagram is available. The one condensed gallium-oxide phase known with confidence is $\mathrm{Ga}_{2} \mathrm{O}_{3}$ (sesquioxide), but evidence exists for a gallium oxide $\left(\mathrm{Ga}_{2} \mathrm{O}\right)$ suboxide phase, which has been reported to decompose at approximately $1075 \mathrm{~K} .^{\prime}$ Some limited thermochemical information is also available in the data

- These calculations are based on a pressurized-water reactor with $21 \mathrm{~kg}$ of plutonium and $441 \mathrm{~kg}$ of uranium, for a total of $524 \mathrm{~kg}$ heavy metal oxide. 
base of the "HSC Chemistry for Windows" software distributed by Outokumpu Research of Finland, ${ }^{2}$ which indicates the phase $\mathrm{Ga}_{2} \mathrm{O}$ as having a melting point of $925 \mathrm{~K}$. These thermochemical data are in general agreement with a heat of reaction determined by Klemm and Schnick. ${ }^{3}$ Given the paucity of thermodynamic information about the suboxide phase, it has not been included in the following thermodynamic analysis, but it should be considered when more information is developed. However, the suboxide will form at lower oxygen activity than does $\mathrm{Ga}_{2} \mathrm{O}_{3}$; therefore, neglecting its presence should be a conservative assumption. Depending on the oxygen potential, ${ }^{*}$ gallium is assumed to be present as the metal or the sesquioxide, $\mathrm{Ga}_{2} \mathrm{O}_{3}$.

The thermodynamic data of Barin ${ }^{4}$ contain the unique set of oxygen potentialtemperature values at which both the metal and oxide coexist and which serve as the boundary separating the formation of the stable oxide from elemental gallium. These values are plotted in Fig. 1 and are indicated by the line labeled $\mathrm{Ga}-\mathrm{Ga}_{2} \mathrm{O}_{3}$. The chemical potential of oxygen increases with increasing temperature indicating that the oxide becomes less stable. At the intersection points of $\mathrm{Ga}_{-} \mathrm{Ga}_{2} \mathrm{O}_{3}$ line with the lines determined by oxygen potential-temperature values for the coexistence of other metal-oxide phases, a temperature is indicated for equal stability of $\mathrm{Ga}_{2} \mathrm{O}_{3}$ and the other oxide. Where the $\mathrm{Ga}-\mathrm{Ga}_{2} \mathrm{O}_{3}$ line is below that of the other oxide (i.e., more negative), $\mathrm{Ga}_{2} \mathrm{O}_{3}$ is more stable. However, where the $\mathrm{Ga}-\mathrm{Ga}_{2} \mathrm{O}_{3}$ line is above that of the other oxide (i.e., less negative), elemental gallium can exist.

The oxygen potential (stability) of the $\mathrm{PuO}_{2}$ phase can be compared to that of the gallium/gallium oxide $\left(\mathrm{Ga}-\mathrm{Ga}_{2} \mathrm{O}_{3}\right)$ boundary. Plutonium dioxide has a wide homogeneity range, with oxygen potential values measured for values of $\mathrm{x}$ in $\mathrm{PuO}_{2-\mathrm{x}}$ as large as $0.3676 .^{5}$ Thus, the dioxide phase can be substantially substoichiometric with resultant oxygen potentials significantly lower than that of nominal $\mathrm{PuO}_{2}$. A representation of the chemical thermodynamic behavior of $\mathrm{PuO}_{2-\mathrm{x}}$ by Besmann and Lindemer ${ }^{6}$ can be used to determine the oxygen potential as a function of composition and temperature. The oxygen potential for stoichiometric $\mathrm{PuO}_{2}$, however, is not uniquely definable because in accordance with the phase rule, this invariant

\footnotetext{
- Oxygen potential is the chemical potential of oxygen and is defined as $R T \ln p^{*}\left[O_{2}\right]$, where $R$ is the ideal gas law constant, $\mathrm{T}$ is absolute temperature in kelvin, and $\mathrm{p}^{*}\left[\mathrm{O}_{2}\right]$ is the oxygen partial pressure normalized to the standard-state partial pressure of $0.101 \mathrm{MPa}(1 \mathrm{~atm})$. This potential determines the stability of various oxygen-containing phases in a system. The variation in chemical potential with temperature and pressure can be expressed by the same equations as for free energy change; thus a decrease (more negative) in chemical potential indicates greater stability.
} 


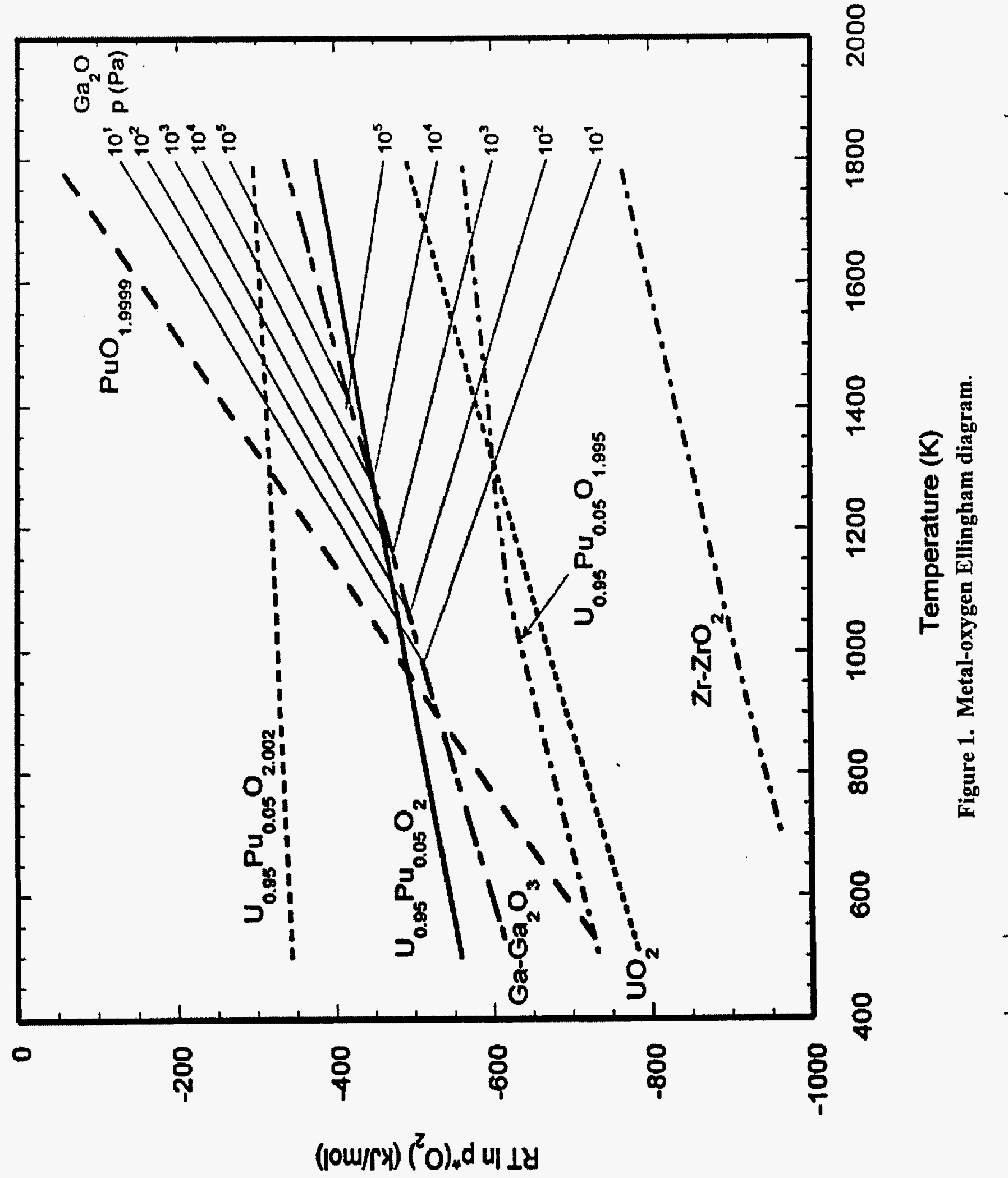


composition can exist over a range of oxygen pressures. $\mathrm{PuO}_{2}$ is effectively a limiting composition because unlike the uranium-oxygen system, there are no condensed plutonium oxides with a higher oxygen-to-metal ratio (O/M) than 2 .

To assess the state of gallium in an "agglomerate" of $\mathrm{PuO}_{2}$, it is assumed that the phase can be approximated by the behavior of $\mathrm{PuO}_{1.9999}$, which is the highest oxygen content composition for which oxygen potential data have been measured. ${ }^{6}$ The temperature-oxygen potential relationship for $\mathrm{PuO}_{2}{ }^{*}$ is given in Fig. 1 based on the model of Besmann and Lindemer. ${ }^{6}$

At higher temperatures $(>900 \mathrm{~K})$, the $\mathrm{PuO}_{2}$ line in the figure lies at oxygen potentials more positive than those for the $\mathrm{Ga}-\mathrm{Ga}_{2} \mathrm{O}_{3}$ equilibrium, indicating that gallium will be present as the oxide with $\mathrm{PuO}_{2}$. Below $\sim 900 \mathrm{~K}$, the opposite prevails, and it is thus possible to have elemental gallium (in solution) in equilibrium with $\mathrm{PuO}_{2}$. (For comparison purposes, the fuel axial centerline temperature for an average rod ranges from 1173 to $1473 \mathrm{~K}$, and the clad interface temperature ranges from 623 to $673 \mathrm{~K}$.) Thus, a very important conclusion from this analysis is, where the local oxygen potential is governed exclusively by the plutonium dioxide phase which is only slightly substoichiometric, elemental gallium can be present at relatively low temperatures.

During burnup, oxygen is released in proportion to the fuel $\mathrm{O} / \mathrm{M}$, so that for every actinide atom fissioned, $\mathrm{O} / \mathrm{M}$ oxygen atoms are released. Because $\mathrm{PuO}_{2}$ is already in its highest oxidation state and cannot accommodate more oxygen, the fission products alone must react with the oxygen released to form oxide phases that tie up the oxygen. The free energy of the reaction to form these oxides governs the priority of the fission products which form oxides. The Ellingham diagram of Kleykamp ${ }^{7}$ indicates the oxygen potential boundaries for the formation of simple oxide fission product phases. Utilizing that information, supplemented by the thermochemical data from Barin, ${ }^{4}$ it is possible to determine the oxidation state of the fission products at a specific burnup.

A set of burnup calculations for $5 \%$ plutonium MOX fuel were performed to determine the fuel composition after $52.5 \mathrm{MWd} / \mathrm{kg}(\sim 5 \%)$ burnup (upper end of the range of worldwide burnup experience), with the resultant fission product concentrations shown in Tables 1 and 2 . It was also assumed that the entire initial concentration of $1 \%$ gallium in the original plutonium alloy was carried over to the fuel. Table 1 also assumes the fuel is prepared such that the gallium

- For convenience, $\mathrm{PuO}_{1.9999}$ is written as $\mathrm{PuO}_{2}$. 
Table 1. Fission product concentrations computed for a burnup of $52.5 \mathrm{MWd} / \mathrm{kg}$ and their oxidation state assuming gallium is present as the oxide in as-fabricated fuel

\begin{tabular}{|c|c|c|c|c|c|c|c|}
\hline $\begin{array}{l}\text { Fission } \\
\text { Product } \\
\text { and } \\
\text { MOX }\end{array}$ & $\begin{array}{c}\text { In Urania } \\
\text { (Atoms/Atom } \\
\text { of Initial } \\
\text { Uranium) }\end{array}$ & $\begin{array}{l}\text { In Plutonia } \\
\text { Aggregate } \\
\text { (Atoms/Atom } \\
\text { of Initial } \\
\text { Plutonium) }\end{array}$ & $\begin{array}{c}\text { Total } \\
\text { (Atoms/Atom } \\
\text { of Initial } \\
\text { Actinide) }\end{array}$ & $\begin{array}{l}\text { Fission } \\
\text { Product } \mathrm{O} / \mathrm{M} \\
\text { in MOX }\end{array}$ & $\begin{array}{l}\text { Oxygen in FP } \\
\text { Oxide in } \\
\text { Homogeneous } \\
\text { MOX } \\
\text { (Atoms/Atom } \\
\text { of Initial } \\
\text { Actinide) } \\
\end{array}$ & $\begin{array}{l}\text { Fission } \\
\text { Product } \mathrm{O} / \mathrm{M} \\
\text { in } \mathrm{PuO}_{2}\end{array}$ & $\begin{array}{l}\text { Oxygen in FP } \\
\text { Oxide in } \\
\text { Plutonia } \\
\text { Aggregate } \\
\text { (Atoms/Atom } \\
\text { of Initial } \\
\text { Plutonium) } \\
\end{array}$ \\
\hline $\mathrm{Se}$ & 8.75E-05 & $2.55 \mathrm{E}-03$ & $2.11 \mathrm{E}-04$ & & & & \\
\hline $\mathrm{Br}$ & $3.42 \mathrm{E}-05$ & $1.00 \mathrm{E}-03$ & $8.27 \mathrm{E}-05$ & & & & \\
\hline $\mathrm{Kr}$ & 4.47E-04 & $1.13 \mathrm{E}-02$ & $9.90 \mathrm{E}-04$ & & & & \\
\hline $\mathrm{Rb}$ & $3.73 \mathrm{E}-04$ & $9.71 \mathrm{E}-03$ & $8.39 \mathrm{E}-04$ & 1.00 & $8.39 \mathrm{E}-04$ & 1.00 & $9.71 \mathrm{E}-03$ \\
\hline $\mathrm{Sr}$ & $9.49 \mathrm{E}-04$ & $2.30 \mathrm{E}-02$ & $2.05 \mathrm{E}-03$ & 1.50 & $3.08 \mathrm{E}-03$ & 1.50 & $3.45 \mathrm{E}-02$ \\
\hline $\mathrm{Y}$ & $4.91 \mathrm{E}-04$ & $1.16 \mathrm{E}-02$ & $1.05 \mathrm{E}-03$ & 1.50 & $1.57 \mathrm{E}-03$ & 1.50 & $1.74 \mathrm{E}-02$ \\
\hline $\mathrm{Zr}$ & $4.46 \mathrm{E}-03$ & $1.24 \mathrm{E}-01$ & $1.04 \mathrm{E}-02$ & 2.00 & $2.08 E-02$ & 2.00 & $2.48 \mathrm{E}-01$ \\
\hline $\mathrm{Nb}$ & $6.56 \mathrm{E}-05$ & 7.39E-04 & $9.93 \mathrm{E}-05$ & 2.00 & $1.99 \mathrm{E}-04$ & 2.00 & $1.48 \mathrm{E}-03$ \\
\hline Mo & $5.00 \mathrm{E}-03$ & $1.58 \mathrm{E}-01$ & $1.26 \mathrm{E}-02$ & 2.00 & $2.53 \mathrm{E}-02$ & 2.00 & $3.16 \mathrm{E}-01$ \\
\hline Tc & $1.20 \mathrm{E}-03$ & $3.51 \mathrm{E}-02$ & $2.90 \mathrm{E}-03$ & & & 2.00 & $7.01 \mathrm{E}-02$ \\
\hline Ru & 4.67E-03 & $1.47 \mathrm{E}-01$ & $1.18 \mathrm{E}-02$ & & & 0.72 & $1.06 \mathrm{E}-01$ \\
\hline $\mathrm{Rh}$ & $9.60 \mathrm{E}-04$ & $2.68 \mathrm{E}-02$ & $2.25 \mathrm{E}-03$ & & & & \\
\hline Pd & $3.11 \mathrm{E}-03$ & $1.28 \mathrm{E}-01$ & 9.37E-03 & & & & \\
\hline $\mathrm{Ag}$ & $2.34 \mathrm{E}-04$ & $7.84 \mathrm{E}-03$ & $6.14 \mathrm{E}-04$ & & & & \\
\hline $\mathrm{Cd}$ & 2.62E-04 & $1.36 \mathrm{E}-02$ & $9.27 \mathrm{E}-04$ & & & 1.00 & $1.36 \mathrm{E}-02$ \\
\hline Sn & $1.09 \mathrm{E}-04$ & $3.74 \mathrm{E}-03$ & $2.90 \mathrm{E}-04$ & & & 2.00 & $7.48 \mathrm{E}-03$ \\
\hline $\mathrm{Sb}$ & $3.13 \mathrm{E}-05$ & $9.06 \mathrm{E}-04$ & $7.50 \mathrm{E}-05$ & & & 1.50 & $1.36 \mathrm{E}-03$ \\
\hline $\mathrm{Te}$ & $6.51 \mathrm{E}-04$ & $2.08 \mathrm{E}-02$ & $1.66 \mathrm{E}-03$ & & & 2.00 & $4.16 \mathrm{E}-02$ \\
\hline I & $3.76 \mathrm{E}-04$ & $1.19 \mathrm{E}-02$ & $9.54 \mathrm{E}-04$ & & & & \\
\hline $\mathrm{Xe}$ & $6.29 \mathrm{E}-03$ & $1.94 \mathrm{E}-01$ & $1.57 \mathrm{E}-02$ & & & & \\
\hline Cs & $3.66 \mathrm{E}-03$ & $1.16 \mathrm{E}-01$ & $9.30 \mathrm{E}-03$ & 1.00 & $9.30 E-03$ & 1.00 & $1.16 \mathrm{E}-01$ \\
\hline $\mathrm{Ba}$ & $1.53 \mathrm{E}-03$ & $5.15 \mathrm{E}-02$ & $4.03 \mathrm{E}-03$ & 1.00 & $4.03 E-03$ & 1.00 & $5.15 E-02$ \\
\hline $\mathrm{La}$ & $1.28 \mathrm{E}-03$ & $3.94 \mathrm{E}-02$ & $3.18 \mathrm{E}-03$ & 1.50 & $4.78 \mathrm{E}-03$ & 1.50 & 5.91E-02 \\
\hline $\mathrm{Ce}$ & $2.84 \mathrm{E}-03$ & $8.29 \mathrm{E}-02$ & $6.84 \mathrm{E}-03$ & 1.50 & $1.03 \mathrm{E}-02$ & 1.50 & $1.24 \mathrm{E}-01$ \\
\hline Pr & $1.13 \mathrm{E}-03$ & $3.53 \mathrm{E}-02$ & $2.84 E-03$ & 1.50 & $4.26 \mathrm{E}-03$ & 1.50 & $5.29 \mathrm{E}-02$ \\
\hline $\mathrm{Nd}$ & $3.57 \mathrm{E}-03$ & $1.13 E-01$ & $9.04 E-03$ & 1.50 & $1.36 \mathrm{E}-02$ & 1.50 & $1.69 \mathrm{E}-01$ \\
\hline Pm & $1.84 \mathrm{E}-04$ & $3.26 \mathrm{E}-03$ & $3.38 \mathrm{E}-04$ & 1.50 & $5.07 \mathrm{E}-04$ & 1.50 & $4.89 \mathrm{E}-03$ \\
\hline $\mathrm{Sm}$ & $8.00 \mathrm{E}-04$ & $2.52 \mathrm{E}-02$ & $2.02 \mathrm{E}-03$ & 1.50 & $3.03 \mathrm{E}-03$ & 1.50 & $3.78 \mathrm{E}-02$ \\
\hline Eu & $2.10 \mathrm{E}-04$ & $7.64 \mathrm{E}-03$ & $5.81 E-04$ & 1.50 & 8.72E-04 & 1.50 & $1.15 \mathrm{E}-02$ \\
\hline Gd & $1.38 \mathrm{E}-04$ & $6.65 \mathrm{E}-03$ & $4.64 \mathrm{E}-04$ & 1.50 & $6.96 \mathrm{E}-04$ & 1.50 & $9.98 \mathrm{E}-03$ \\
\hline $\mathrm{Tb}$ & $4.45 \mathrm{E}-06$ & $1.91 \mathrm{E}-04$ & 4.23E-06 & 1.50 & $6.34 \mathrm{E}-06$ & 1.50 & $2.87 \mathrm{E}-04$ \\
\hline Dy & & $1.06 \mathrm{E}-04$ & $5.32 \mathrm{E}-06$ & 1.50 & $7.98 \mathrm{E}-06$ & 1.50 & $1.60 \mathrm{E}-04$ \\
\hline \multirow[t]{3}{*}{ MOX } & & & & & $5.00 \mathrm{E}-03$ & & \\
\hline & & & & Total & $1.08 \mathrm{E}-01$ & & 1.50 \\
\hline & & & & $\begin{array}{l}\text { Oxygen } \\
\text { Released }\end{array}$ & $1.08 \mathrm{E}-01$ & & 1.50 \\
\hline
\end{tabular}


Table 2. Fission product concentrations computed for a burnup of $52.5 \mathrm{MWd} / \mathrm{kg}$ and their oxidation state assuming gallium is present unoxidized in as-fabricated fuel

\begin{tabular}{|c|c|c|c|c|c|c|c|}
\hline $\begin{array}{l}\text { Fission } \\
\text { Product } \\
\text { Ga and } \\
\text { MOX }\end{array}$ & $\begin{array}{l}\text { In Urania } \\
\text { (Atoms/Atom } \\
\text { of Initial } \\
\text { Uranium) }\end{array}$ & $\begin{array}{c}\text { In Plutonia } \\
\text { Aggregate } \\
\text { (Atoms/Atom } \\
\text { of Initial } \\
\text { Plutonium) }\end{array}$ & $\begin{array}{c}\text { Total } \\
\text { (Atoms/Atom } \\
\text { of Initial } \\
\text { Actinide) }\end{array}$ & $\begin{array}{c}\text { Fission } \\
\text { Product } \mathrm{O} / \mathrm{M} \\
\text { in } \mathrm{MOX}\end{array}$ & $\begin{array}{l}\text { Oxygen in FP } \\
\text { Oxide in } \\
\text { Homogeneous } \\
\text { MOX } \\
\text { (Atoms/Atom } \\
\text { of Initial } \\
\text { Actinide) }\end{array}$ & $\begin{array}{c}\text { Fission } \\
\text { Product } \mathrm{O} / \mathrm{M} \\
\text { in Plutonia }\end{array}$ & $\begin{array}{l}\text { Oxygen in FP } \\
\text { Oxide in } \\
\text { Plutonia } \\
\text { Aggregate } \\
\text { (Atoms/Atom } \\
\text { of Initial } \\
\text { Plutonium) } \\
\end{array}$ \\
\hline $\mathrm{Se}$ & $8.75 \mathrm{E}-05$ & $2.55 \mathrm{E}-03$ & $2.11 \mathrm{E}-04$ & & & & . \\
\hline $\mathrm{Br}$ & $3.42 \mathrm{E}-05$ & $1.00 \mathrm{E}-03$ & $8.27 \mathrm{E}-05$ & & & & \\
\hline $\mathrm{Kr}$ & $4.47 \mathrm{E}-04$ & $1.13 \mathrm{E}-02$ & $9.90 \mathrm{E}-04$ & & & & \\
\hline $\mathrm{Rb}$ & 3.73E-04 & $9.71 \mathrm{E}-03$ & 8.39E-04 & 1.00 & 8.39E-04 & 1.00 & $9.71 \mathrm{E}-03$ \\
\hline $\mathrm{Sr}$ & $9.49 \mathrm{E}-04$ & 2.30E-02 & $2.05 \mathrm{E}-03$ & 1.00 & $2.05 \mathrm{E}-03$ & 1.00 & 2.30E-02 \\
\hline$Y$ & $4.91 \mathrm{E}-04$ & $1.16 \mathrm{E}-02$ & $1.05 \mathrm{E}-03$ & 1.50 & $1.57 \mathrm{E}-03$ & 1.50 & $1.74 \mathrm{E}-02$ \\
\hline $\mathrm{Zr}$ & $4.46 \mathrm{E}-03$ & 0.1237928 & $1.04 \mathrm{E}-02$ & 2.00 & $2.08 \mathrm{E}-02$ & 2.00 & $2.48 \mathrm{E}-01$ \\
\hline $\mathrm{Nb}$ & $6.56 \mathrm{E}-05$ & $7.39 \mathrm{E}-04$ & 9.93E-05 & 2.00 & $1.99 \mathrm{E}-04$ & 2.00 & $1.48 \mathrm{E}-03$ \\
\hline Mo & $5.00 \mathrm{E}-03$ & $1.58 \mathrm{E}-01$ & $1.26 \mathrm{E}-02$ & 2.00 & $2.53 \mathrm{E}-02$ & 2.00 & $3.16 \mathrm{E}-01$ \\
\hline Tc & $1.20 \mathrm{E}-03$ & $3.51 \mathrm{E}-02$ & $2.90 \mathrm{E}-03$ & & & 2.00 & 7.01E-02 \\
\hline $\mathrm{Ru}$ & 4.67E-03 & $1.47 \mathrm{E}-01$ & $1.18 \mathrm{E}-02$ & & & 0.43 & $6.33 \mathrm{E}-02$ \\
\hline $\mathbf{R h}$ & $9.60 \mathrm{E}-04$ & $2.68 \mathrm{E}-02$ & $2.25 \mathrm{E}-03$ & & & & \\
\hline $\mathrm{Pd}$ & $3.11 \mathrm{E}-03$ & $1.28 \mathrm{E}-01$ & 9.37E-03 & & & & \\
\hline $\mathrm{Ag}$ & 2.34E-04 & $7.84 \mathrm{E}-03$ & $6.14 \mathrm{E}-04$ & & & & \\
\hline $\mathrm{Cd}$ & $2.62 \mathrm{E}-04$ & $1.36 \mathrm{E}-02$ & 9.27E-04 & & & 1.00 & $1.36 \mathrm{E}-02$ \\
\hline $\mathrm{Sn}$ & $1.09 \mathrm{E}-04$ & $3.74 \mathrm{E}-03$ & $2.90 \mathrm{E}-04$ & & & 2.00 & $7.48 \mathrm{E}-03$ \\
\hline $\mathrm{Sb}$ & $3.13 \mathrm{E}-05$ & $9.06 \mathrm{E}-04$ & 7.50E-05 & & & 1.50 & $1.36 \mathrm{E}-03$ \\
\hline $\mathrm{Te}$ & $6.51 \mathrm{E}-04$ & $2.08 \mathrm{E}-02$ & $1.66 \mathrm{E}-03$ & & & 2.00 & $4.16 \mathrm{E}-02$ \\
\hline I & $3.76 \mathrm{E}-04$ & $1.19 \mathrm{E}-02$ & $9.54 \mathrm{E}-04$ & & & & \\
\hline $\mathrm{Xe}$ & $6.29 \mathrm{E}-03$ & $1.94 \mathrm{E}-01$ & $1.57 \mathrm{E}-02$ & & & & \\
\hline Cs & $3.66 \mathrm{E}-03$ & $1.16 \mathrm{E}-01$ & $9.30 \mathrm{E}-03$ & 1.00 & 9.30E-03 & 1.00 & $1.16 \mathrm{E}-01$ \\
\hline $\mathrm{Ba}$ & $1.53 \mathrm{E}-03$ & $5.15 \mathrm{E}-02$ & $4.03 \mathrm{E}-03$ & 1.00 & $4.03 E-03$ & 1.00 & $5.15 E-02$ \\
\hline $\mathbf{L a}$ & $1.28 \mathrm{E}-03$ & $3.94 \mathrm{E}-02$ & $3.18 \mathrm{E}-03$ & 1.50 & 4.78E-03 & 1.50 & $5.91 \mathrm{E}-02$ \\
\hline $\mathrm{Ce}$ & $2.84 \mathrm{E}-03$ & 8.29E-02 & $6.84 \mathrm{E}-03$ & 1.50 & $1.03 E-02$ & 1.50 & $1.24 \mathrm{E}-01$ \\
\hline Pr & $1.13 \mathrm{E}-03$ & $3.53 \mathrm{E}-02$ & 2.84E-03 & 1.50 & $4.26 \mathrm{E}-03$ & 1.50 & $5.29 \mathrm{E}-02$ \\
\hline Nd & 3.57E-03 & $1.13 \mathrm{E}-01$ & 9.04E-03 & 1.50 & $1.36 \mathrm{E}-02$ & 1.50 & $1.69 \mathrm{E}-01$ \\
\hline $\mathrm{Pm}$ & $1.84 \mathrm{E}-04$ & $3.26 \mathrm{E}-03$ & 3.38E-04 & 1.50 & $5.07 \mathrm{E}-04$ & 1.50 & $4.89 \mathrm{E}-03$ \\
\hline $\mathrm{Sm}$ & 8.00E-04 & $2.52 \mathrm{E}-02$ & 2.02E-03 & 1.50 & $3.03 E-03$ & 1.50 & $3.78 \mathrm{E}-02$ \\
\hline $\mathrm{Eu}$ & $2.10 \mathrm{E}-04$ & $7.64 \mathrm{E}-03$ & 5.81E-04 & 1.50 & 8.72E-04 & 1.50 & $1.15 \mathrm{E}-02$ \\
\hline Gd & $1.38 \mathrm{E}-04$ & $6.65 \mathrm{E}-03$ & $4.64 \mathrm{E}-04$ & 1.50 & $6.96 \mathrm{E}-04$ & 1.50 & 9.98E-03 \\
\hline $\mathrm{Tb}$ & $4.45 \mathrm{E}-06$ & $1.91 \mathrm{E}-04$ & 4.23E-06 & 1.50 & $6.34 \mathrm{E}-06$ & 1.50 & 2.87E-04 \\
\hline Dy & & $1.06 \mathrm{E}-04$ & $5.32 \mathrm{E}-06$ & 1.50 & 7.98E-06 & 1.50 & $1.60 \mathrm{E}-04$ \\
\hline $\mathrm{Ga}$ & & $3.35 \mathrm{E}-02$ & $1.68 \mathrm{E}-03$ & 1.50 & 2.51E-03 & 1.50 & 5.03E-02 \\
\hline \multirow[t]{3}{*}{ MOX } & & & & & $3.00 \mathrm{E}-03$ & & \\
\hline & & & & Total & $1.08 \mathrm{E}-01$ & & 1.50 \\
\hline & & a & & $\begin{array}{l}\text { Oxygen } \\
\text { Released }\end{array}$ & $1.08 \mathrm{E}-01$ & & 1.50 \\
\hline
\end{tabular}


is present as the oxide, whereas Table 2 assumes the gallium in the fuel is elemental (lower $\mathrm{O} / \mathrm{M}$ fuel). The fission product atoms formed per initial atom of either uranium or plutonium are given in the second and third columns of both tables. The second column shows the fission product concentration because of fissioning of uranium and uranium transmuted to ${ }^{239} \mathrm{Pu}$, and the third column shows the concentration because of fissioning of the initial ${ }^{239} \mathrm{Pu}$ in the asfabricated fuel. The fourth column shows the proportional sum of the previous two columns and is the total fission product inventory. The tables also give the $\mathrm{O} / \mathrm{M}$ ratio for each of the fission products that form oxides based on the release of oxygen during fissioning and their thermochemistry. If an $\mathrm{O} / \mathrm{M}$ value is not given, it means that either the element does not form an oxide or that the oxygen potential is insufficient to form the metal oxide. Column six represents the amount of fission-released oxygen consumed by the fission products in forming oxides per atom of initial actinide atom. The fission products were allowed to form oxides based on their thermochemical affinity for oxygen until all the fission-released oxygen was consumed. Note that, with the exception of cesium and rubidium, which are assumed to form uranates, all the fission products that oxidize are assumed to form simple oxides. The formation of complex oxides is considered in the later section on fission products. The initial $\mathrm{O} / \mathrm{M}$ of the fuel is assumed to be 2 .

The last two columns in Tables 1 and 2 were developed assuming the fuel contains isolated aggregate grains of plutonia in which all the gallium resides, with the fission products bred solely into the plutonia accommodating the fission-released oxygen. In the case where gallium is present as the oxide in as-fabricated fuel (Table 1), gallium is expected to remain as the oxide during burn-up. A number of the metallic fission products will form oxides, either in solution with the fuel or as independent phases, as indicated in Table 1.

The oxide phases that will form are seen to be somewhat different from those observed in typical LWR fuel. ${ }^{7}$ LWR fuel will have metallic precipitates containing molybdenum, technetium, cadmium, tin, antimony, and tellurium; however, under the assumption that in the MOX fuel the plutonia remains as an isolated aggregate, these metals are present as oxides. The oxygen balance also indicates a portion of the ruthenium will exist as oxide [i.e., the $\mathrm{O} / \mathrm{M}$ ratios in Tables 1 and 2 are a fraction of the value of 2 for ruthenium dioxide $\left(\mathrm{RuO}_{2}\right)$ ]. The presence of these fission products as oxides instead of metallic precipitates should not have a negative effect on fuel behavior unless they form precipitates whose volume increase causes mechanical deformation. 
However, if gallium is elemental in the unirradiated fuel, it will form an oxide phase with fissioned-released oxygen. As shown in Table 2, gallium present at the 1 mass \% level has little effect on the oxidation state of the fission products.

\subsubsection{Bulk Fuel Chemistry}

In this section we assume that the MOX fuel exists as a true solid solution of $5 \%$ plutonia (with gallium) in urania, and we can consider the phase as $\mathrm{U}_{0.95} \mathrm{Pu}_{0.05} \mathrm{O}_{2 \pm \mathrm{x}}$.

\subsubsection{Oxide formation}

Besmann and Lindemer, ${ }^{6}$ as an extension of the work on $\mathrm{PuO}_{2-\mathrm{x}}$, have developed a chemical thermodynamic representation of the fluorite structure MOX. The equations detailing the representation are complex and are not included in this report, but can be found in ref. 6 . Utilizing these relationships, the temperature-oxygen potential relationship for $\mathrm{U}_{0.95} \mathrm{Pu}_{0.05} \mathrm{O}_{2 \pm x}$ can be determined and the expressions for the nominal production stoichiometries of $\mathrm{U}_{0.95} \mathrm{Pu}_{0.05} \mathrm{O}_{2}$, $\mathrm{U}_{0.95} \mathrm{Pu}_{0.05} \mathrm{O}_{2.002}$, and $\mathrm{U}_{0.95} \mathrm{Pu}_{0.05} \mathrm{O}_{1.995}$ are plotted in Fig. 1. The slopes of the lines are significantly different from those for $\mathrm{PuO}_{2}$. For comparison purposes, the line for stoichiometric $\mathrm{UO}_{2}$ is also shown. The $\mathrm{Ga}-\mathrm{Ga}_{2} \mathrm{O}_{3}$ equilibrium exists at a more positive oxygen potential above $\sim 1260 \mathrm{~K}$ for $\mathrm{U}_{0.95} \mathrm{Pu}_{0.05} \mathrm{O}_{2}$. This implies that should the $\mathrm{U}_{0.95} \mathrm{Pu}_{0.05} \mathrm{O}_{2}$ phase determine the oxygen potential, $\mathrm{Ga}_{2} \mathrm{O}_{3}$ can only be reduced to the metal in regions of the fuel above $\sim 1260 \mathrm{~K}$. However, should the oxygen potential be determined by $\mathrm{U}_{0.95} \mathrm{Pu}_{0.05} \mathrm{O}_{1.995}$, elemental gallium would be the stable phase over the entire temperature range. Finally, hyperstoichiometric $\mathrm{U}_{0.95} \mathrm{Pu}_{0.05} \mathrm{O}_{2.002}$ would allow gallium to remain an oxide over the entire temperature range.

Again, for the homogeneous fuel, during burnup most of the metallic fission products can form oxide phases. In addition, unlike pure plutonia, the fuel can accommodate more oxygen in its fluorite structure. As a result, the oxygen balances in Tables 1 and 2 for homogeneous fuel were computed to leave a small fraction of oxygen that can combine with the fuel, thereby increasing the hyperstoichiometry of the fuel. The chemical state of the fission products are essentially the same as for typical LWR fuel.

Thus, for two scenarios, [gallium with $\mathrm{PuO}_{2-\mathrm{x}}$ (below $900 \mathrm{~K}$ ) and $\mathrm{U}_{0.95} \mathrm{Pu}_{0.05} \mathrm{O}_{2-x}$ (for the entire temperature range shown in Fig. 1)] substoichiometric dioxide phases can lead to the presence of gallium metal in the fuel. To minimize any differences between conventional MOX and gallium-containing MOX, it is necessary to ensure that the gallium is oxidized, thus allowing 
for the oxidation of most metallic fission products. This can be achieved by ensuring that the initial gallium is fully oxidized and that the initial $\mathrm{O} / \mathrm{M}$ ratio of the MOX is at least 2.

\subsubsection{Reactions with Fission Products}

$\mathrm{Ga}_{2} \mathrm{O}_{3}$ reacts with rare earth oxides to form two types of compounds: $\mathrm{LnGaO}_{3}$ and $3 \mathrm{Ln}_{2} \mathrm{O}_{3} \cdot 5 \mathrm{Ga}_{2} \mathrm{O}_{3}$, where $\mathrm{Ln}$ is a rare earth element.' In addition to these rare earth oxide $-\mathrm{Ga}_{2} \mathrm{O}_{3}$ compounds, complex gallates of the type $\mathrm{GaLnGa}_{3} \mathrm{O}_{7}$, where $\mathrm{Ln}=\mathrm{La}, \mathrm{Pr}, \mathrm{Nd}$, or $\mathrm{Sm}$, have been reported. ${ }^{4}$

$\mathrm{Ga}_{2} \mathrm{O}_{3}$, heated with barium carbonate forms $\mathrm{BaO} \cdot \mathrm{Ga}_{2} \mathrm{O}_{3}$. It is likely that the same gallate would form with $\mathrm{BaO}$ and $\mathrm{Ga}_{2} \mathrm{O}_{3}$ as the starting materials. Similarly, compounds of the type $\mathrm{M}_{2} \mathrm{O} \cdot 6 \mathrm{Ga}_{2} \mathrm{O}_{3}$, where $\mathrm{M}=\mathrm{Rb}$ or $\mathrm{Cs}$ are formed by sintering the alkali metal ( $\mathrm{Rb}$ or $\mathrm{Cs}$ ) carbonate with $\mathrm{Ga}_{2} \mathrm{O}_{3}$.

Although elemental gallium reacts with iodine to form gallium iodide $\left(\mathrm{GaI}_{3}\right)$, this reaction will not occur in the presence of fission products $\mathrm{La}, \mathrm{Ba}$, or $\mathrm{Cs}$ or $\mathrm{Zr}$ from the cladding. Furthermore, $\mathrm{Ga}_{2} \mathrm{O}_{3}$ will not be converted to the iodide by reaction with iodine.

Accordingly, the most probable reactions of fission products with gallium will lead to the formation of mixed oxides with rare earths, alkaline earths, or alkali metals. These reactions would reduce the chemical activity of the gallium (increased gallium thermodynamic stability) compared to its initial activity in the absence of fission products; however, the melting points of the fission product compounds could be decreased and the volatility increased compared to $\mathrm{Ga}_{2} \mathrm{O}_{3}$ (increased tendency for gallium transport).

\subsection{GALLIUM TRANSPORT MECHANISMS WITHIN FUEL}

Given that gallium is present in the fuel, before it can react with the cladding, it must be able to collect at the fuel-cladding interface. Two possible transport mechanisms, gas phase and solid-state diffusion, are discussed in this section.

\subsubsection{Gas Phase Transport}

Possible mechanisms for gas phase transport are simple vaporization and condensation and chemical vapor (coupled) transport. Near the oxygen potentials for MOX fuel, as shown in Fig. 1, the dominant gaseous species will be $\mathrm{Ga}_{2} \mathrm{O}$. The only other gaseous species are elemental gallium and $\mathrm{GaO}$, with only the gallium vapor pressure exceeding that of $\mathrm{Ga}_{2} \mathrm{O}$ at oxygen 
potentials well below those of the $\mathrm{Ga}-\mathrm{Ga}_{2} \mathrm{O}$ equilibrium. The $\mathrm{Ga}_{2} \mathrm{O}$ vapor pressures in the presence of $\mathrm{Ga}_{2} \mathrm{O}_{3}$ are governed by the reaction:

$$
\mathrm{Ga}_{2} \mathrm{O}_{3}(\mathrm{~s})=\mathrm{Ga} a_{2} \mathrm{O}(\mathrm{g})+\mathrm{O}_{2}(\mathrm{~g})
$$

Using the thermochemical data of Table 3, the oxygen potential expression for values of the vapor pressure of $\mathrm{Ga}_{2} \mathrm{O}(\mathrm{g})$ over $\mathrm{Ga}_{2} \mathrm{O}_{3}(l)$ is

$$
R T \ln p_{\mathrm{O}_{2}}^{*}=970137-371.441 T+R T \ln p_{\mathrm{Ga}_{2} \mathrm{O}}
$$

Table 3. Thermodynamic values at $1000 \mathrm{~K}$ for the gallium-oxygen system

\begin{tabular}{ccccccc}
\hline & & $\mathbf{G a}(l)$ & $\mathrm{O}_{2}(\mathrm{~g})$ & $\mathbf{G a}_{2} \mathrm{O}_{3}$ & $\mathbf{G a}_{2} \mathrm{O}(\mathrm{g})$ & $\mathbf{G a O}(\mathbf{g})$ \\
\hline$\Delta \mathrm{H}_{\mathrm{f}}^{\circ}$ & $\mathrm{kJ} / \mathrm{mol}$ & - & - & -1091208 & -121071 & 133973. \\
$\mathrm{~S}^{\circ}$ & $\mathrm{J} /(\mathrm{mol} \mathrm{K})$ & 91.859 & 243.578 & 220.136 & 347.999 & 279.381 \\
\hline
\end{tabular}

Source: I. Barin Thermochemical Data of Pure Substances, VCH, Germany (1989).

At lower oxygen potentials, where elemental gallium is the stable condensed phase as opposed to the oxide, the vapor pressure of $\mathrm{Ga}_{2} \mathrm{O}$ is determined from:

$$
2 \mathrm{Ga}(l)+1 / 2 \mathrm{O}_{2}(g)=G a_{2} \mathrm{O}(g)
$$

Using the data of Table 3, the oxygen potential can be expressed as:

$$
R T \ln p_{\mathrm{O}_{2}}^{*}=-242142-84.984 T+R T \ln p_{\mathrm{Ga}_{2} \mathrm{O}}
$$

At temperatures $>1200 \mathrm{~K}$, the vapor pressure of gaseous $\mathrm{Ga}_{2} \mathrm{O}$ will be of the order of $10^{4}$ to $10^{5} \mathrm{~Pa}$. In a temperature gradient within the fuel pin, the oxide species may largely vaporize in the hotter regions causing transport of the gallium oxide to the cooler clad surfaces where it 
will condense. The above vapor pressures presume that the condensed gallium species are present as separate phases within the fuel, yet no reason exists why gallium, regardless of its oxidation state, could not be dissolved in the fluorite structure of the fuel. In that case, the equilibrium behavior of the gallium would be modified by its solution in the fuel and be governed by its activity in the solution. In the absence of data with regard to the activity of gallium in either plutonia or urania-plutonia, the best assumption, as demonstrated by LANL, ${ }^{8}$ is to presume that no energetic interactions exists between the species and that the system acts as an ideal solid solution. That being the case, the activity of the dissolved gallium species would simply be in direct proportion to its concentration. As a result, the vapor pressure of $\mathrm{Ga}_{2} \mathrm{O}$, or any other gallium species such as those described by the previously noted expressions and shown in Fig. 1, would be reduced by a factor equal to the molar concentration of the dissolved gallium species:

$$
p_{G a_{2} O}(\text { soln. })=\frac{G a}{G a_{2} O_{3}}(\text { soln. }) p_{G a_{2} O},
$$

where $\left[\mathrm{Ga} / \mathrm{Ga}_{2} \mathrm{O}_{3}\right]$ is the molar concentration of either elemental gallium or $\mathrm{Ga}_{2} \mathrm{O}_{3}$ in the $\mathrm{MOX}$ fuel. This reduction would be significant because of the low concentration of gallium present. Figure I shows that elevated oxygen pressures suppress the $\mathrm{Ga}_{2} \mathrm{O}$ vapor pressure over $\mathrm{Ga}_{2} \mathrm{O}_{3}$, and thus significant burnup could serve to reduce gallium transport.

With no other gallium-containing, relatively high vapor pressure species with which $\mathrm{Ga}_{2} \mathrm{O}$ can form a vapor transport couple, deposition of metallic gallium on the clad via such a process is not possible. As noted earlier, this does not preclude simple vaporization of $\mathrm{Ga}_{2} \mathrm{O}$ with subsequent condensation on the clad. Such gas-phase diffusion and deposition, however, would not be limited to the gallium system, but is possible for other, similarly behaving, fission product elements.

\subsubsection{Solid-State Transport}

In addition to any gas phase transport of gallium species to the fuel-clad interface, there are potential mechanisms by which gallium transport could occur in the solid state. These include the following: 
- volume diffusion of gallium driven by gradients in gallium concentration (flux from high to low concentrations);

- enhanced concentration gradient driven volume diffusion where the flux of gallium is accelerated through grain boundaries, dislocations, etc.;

- volume diffusion of gallium driven by a temperature gradient (thermal diffusion) with the possibility that the gallium flux may be either up or down the temperature gradient;

- concentration gradient driven surface diffusion of gallium on either internal or external surfaces (e.g. cracks in the mixed oxide fuel);

- thermal surface diffusion of gallium from hot to cold regions; and

- $\quad$ irradiation-driven diffusion of gallium.

At the present time no information exists on which of these diffusion mechanisms may be effective in moving gallium to the fuel-clad interface during operation of the MOX fuel. Thermodynamically, it is expected that gallium will be present (based on expected fuel fabrication conditions) initially as $\mathrm{Ga}_{2} \mathrm{O}_{3}$, and that this oxide should become increasingly stable as burnup progresses (see Sect. 2.2.1). It can be postulated that the volume diffusion of gallium in this chemical form could be relatively slow. However, if it is present as elemental gallium, transport is expected to be faster than if it is present as an oxide. Also, diffusive mass transport rates and dominant mechanisms should be expected to change continuously as burnup progresses and the original structure and nature of the MOX fuel is changed and degraded. For example, cracking of the fuel pellets will occur as a result of thermal cycling, and this would tend to increase the importance of surface diffusion internal to the fuel pellets as a gallium transport mechanism. Such cracking could also provide an avenue for gas phase transport.

As indicated in Sect. 2.2.1, the gallium may likely be concentrated in the $\mathrm{PuO}_{2}$ agglomerates. This will provide local concentration gradients favoring movement of the gallium into the $\mathrm{UO}_{2}$ matrix. Because no significant overall concentration gradient of gallium relative to the bulk fuel pellet is expected, there should be little driving force for transport of gallium to the fuel-clad interface as a result of concentration-dependent diffusion mechanisms. Also, early in the life of the MOX fuel when plutonium agglomerate fissions predominate, locally higher temperatures will likely occur in the agglomerates. This would provide local temperature gradients to further disperse gallium into the matrix but only if the thermal diffusion characteristic of the gallium diffusing species in MOX fuel is a flux from high to low temperatures. There is a larger potential for thermal diffusion, both volume and surface, as a 
result of the very large radial temperature gradients in the MOX fuel pellets. (Axial gradients will also exist but will be much less severe.) Although any thermal surface diffusion that occurs will be from high to low temperatures (toward the fuel-clad interface), the direction of the gallium flux in the bulk material is not currently known.

In summary, neither the dominant mechanisms by which gallium might be transported in the MOX fuel matrix in the solid state nor the rates for such transfer mechanisms are known. This is further complicated by the physical and chemical changes expected in the fuel as burnup progresses. Therefore, it is impossible at present to predict whether gallium will be transported to the fuel-clad interface as a result of solid-state transport mechanisms. 


\section{CLAD PERFORMANCE AND DEGRADATION MECHANISMS}

\subsection{INTRODUCTION}

This section discusses any likely impacts of gallium on the known corrosion mechanisms of Zircaloy with water and MOX fuel, respectively, and if these additional potential mechanisms need to be evaluated. Within the limitation of the available data, consideration is given to other types of corrosion/cracking mechanisms that could be introduced by the presence of gallium.

As a result of their overall favorable nuclear, mechanical, and corrosion properties, zirconium alloys (i.e., Zircaloy and $\mathrm{Zr}-\mathrm{Nb}$ ) are used as fuel cladding in water-cooled reactors. Alloying elements include $\mathrm{Sn}, \mathrm{Fe}, \mathrm{Cr}$, and $\mathrm{Nb}$, and extensive work has been done to determine how these alloying additions affect corrosion. With the exception of tin, these alloying elements have very low solubilities in zirconium and form second-phase particles if slowly cooled from the beta phase or if annealed in the alpha phase after rapid cooling from the beta phase.

The amount of alloying element in the matrix and second-phase particles, and the particle size distribution determine resistance to both uniform and localized accelerated (nodular) corrosion in water, the effect depending on concentration and morphology. Corrosion studies have generally focused on uniform corrosion of Zircaloy-4 in PWRs and on nodular formation on Zircaloy-2 in boiling water reactors (BWRs). Other important aspects of water-side corrosion include stress corrosion cracking (SCC) of stainless steel components (e.g., recirculation-line cracking in BWRs), hydriding, and transport of radioactivity (radiation transport) to the heat exchangers.

Compatibility of Zircaloy cladding with $\mathrm{UO}_{2}$ and $\mathrm{MOX}$ fuels has been examined both inand out-of-pile. Under conditions of high burnup (both simulated and in-reactor), brittle failure of the cladding has been observed in the form of through-wall cracks that initiate at the inside tube surface. A pellet-clad interaction (PCI) mechanism has been described that involves local deformation and certain embrittling fission products. Studies have indicated that gaseous iodine or cadmium-containing environments play a critical role in PCI failures. Inner surface liners of zirconium have been effective in mitigating this type of failure in BWRs, and minimization of the stress and heating rate have been effective in PWRs.

Because the development of through-wall cracks in the cladding is of critical concern in assessing fuel-clad performance, several forms of corrosion that can produce cracking in metals must be considered relative to possible impacts of gallium. Four of the principal mechanisms that can lead to environmentally induced cracking are 
- SCC,

- hydrogen embrittlement (HE),

- liquid metal embrittlement (LME), and

- $\quad$ solid metal induced embrittlement (SMIE).

Gas-phase embrittlement mechanisms are not listed separately from hydrogen embrittlement, but gaseous elements can produce similar effects as well. All of the cited forms of embrittlement require the presence of a tensile stress in the material but, in general, there are many differences in the circumstances under which they occur.

In aqueous environments, susceptible metals can undergo time-dependent subcritical crack propagation, called SCC. Some confusion exists, however, because the term SCC has come to be used generically to describe any form of environmentally induced/stress-assisted cracking.

Cracking, blistering, hydride formation, and loss in tensile ductility are all forms of hydrogen damage or hydrogen embrittlement. Mechanisms that are of particular interest in the present evaluation are

- $\quad$ hydrogen trapping (i.e., bonding of hydrogen to impurities or defects);

- $\quad$ hydride formation (i.e., formation of a brittle phase that cracks easily);

- decohesion (i.e., lowering of the cohesive force between metal atoms);

- $\quad$ enhanced plastic flow (i.e., atomic hydrogen enhanced dislocation motion); and

- $\quad$ internal pressure-induced cracking (i.e., accumulation of hydrogen at voids or grain boundaries causing high internal pressures that grow cracks).

LME is thought to result from the chemisorption-induced reduction in strength of atomic bonding in the solid material in regions of stress concentrations. This type of embrittlement is different from corrosion embrittlement that can occur from intergranular penetration in the absence of stress. With LME, grain boundary penetration before the initiation of cracking does not appear to occur; however, several prerequisites are generally applicable:

- tensile stress,

- plastic flow,

- polycrystalline material, and

- wetting/chemisorption.

Other observations relative to LME have been that only certain (but unpredictable) combinations of materials are susceptible; LME is unlikely when high mutual solubility exists between solid and liquid metals; LME is unlikely when the liquid and solid metal form a high 
melting intermetallic compound; LME is more severe near the melting temperature of the liquid metal and usually decreases with increasing temperature; and a rapid change from no embrittlement to embrittlement can occur if the tensile strength of the alloy increases, such as is likely during irradiation.

SMIE generally has similar prerequisites as LME. However, incubation periods are much longer, indicating that the crack initiation process is different. Overall rates are also much slower.

\subsection{FUEL-SIDE CORROSION}

Fuel-side corrosion refers to the corrosion that may occur on the fuel-side of the cladding.

\subsubsection{Environment/Burnup}

The effect of gallium on fuel-side corrosion will depend on several factors (discussed previously) that are influenced both by fuel fabrication processing and chemical and physical changes accruing in the fuel during burnup:

- the concentration and morphology of gallium-distributed uniformly as a solute or distributed as dispersed agglomerates;

- the oxidation potential of the as-fabricated oxide fuel;

- changes in oxidation potential resulting from fission product buildup, transmutation of gallium, and gallium transport to the cladding;

- chemical reaction of the gallium with fission products and fuel constituents; and - changes in fuel density and porosity and breakup of the fuel.

The products accruing from gallium transmutation (principally germanium) will be at such low concentrations in the fuel that they should not contribute to the normal degradation of cladding by fission products.

In Sect. 2.1, two levels of concentration of gallium were mentioned: $1 \%$ in the plutonium used to make MOX fuel and $10 \mathrm{ppm}$ in processed fuel. At the $1 \%$ level, the gallium could influence overall chemistry of the fuel during its life whereas at $10 \mathrm{ppm}$, it seems unlikely to do so. As discussed in Sect. 2.2, the oxygen potential of the reference MOX fuel at reactor startup can be such that either gallium or $\mathrm{Ga}_{2} \mathrm{O}_{3}$ is stable. Substoichiometry of the MOX fuel and higher 
temperature favor the stability of gallium. However, fission physics calculations indicate that the oxidation potential will increase and should exceed that needed for the stabilization of $\mathrm{Ga}_{2} \mathrm{O}_{3}$ during fuel burnup.

As discussed in Sect. 2.2.3, the interaction of gallium with fission products in MOX fuel could potentially lead to the formation of mixed oxides between $\mathrm{Ga}_{2} \mathrm{O}_{3}$ and rare earths, alkaline earths, or alkali metals. None of these reactions would be expected to affect corrosion of the cladding compared to reactions occurring in MOX fuels without gallium. Likewise, gallium is not expected to affect the chemical state of the fission product iodine, one of the principal contributors to PCI failures (Sect. 2.2.3). The one class of fission product interaction with Zircaloy cladding which gallium could enhance involves elements that potentially can cause LME. Based on laboratory tests, cadmium (in oxide fuel) has been shown to induce Zircaloy cracking, and the mechanism has been attributed to LME. Accordingly, it is possible that any LME effects related to the fission product cadmium could be magnified when gallium is also present (i.e., a synergism may exist between the LME effects of cadmium and gallium, as discussed in the next section).

Transport of gallium (Section 2.3) in the system depends upon a number of factors, most of which cannot be quantified at this time. However, the corrosion mechanisms that are discussed below generally presume some method for gallium transport.

\subsubsection{Material Variables}

Because the solubilities of gallium in zirconium and zirconium in gallium at temperatures of interest are relatively low, ${ }^{9}$ any interalloying of gallium with the Zircaloy cladding should lead to the formation of intermetallic compounds, which are characteristically brittle. However, given the small amount of gallium in the fuel compared to the surface area and volume of cladding, such interalloying (corrosion) would be superficial, and apart from the possibility of grain boundary embrittlement discussed in Sect. 3.2.4, is not expected to affect the metallurgical integrity of the cladding. Gallium does form a low-melting eutectic system with tin, a minor alloying addition to Zircaloy. However, considering that tin is present as a dilute solid solute in a zirconium solvent, it is unlikely that tin-gallium eutectic will form by the diffusion of trace quantities of gallium into the cladding. While the collection of liquid gallium on the cladding surface could in principle dissolve tin from the alloy, the mass of gallium is likely too small for this effect to impact the chemistry or metallurgy of the cladding. 


\subsubsection{Pellet Clad Interaction}

Pellet-clad interaction leading to failure in Zircaloy fuel cladding has been attributed to the presence of stresses in the cladding and one or more aggressive chemical species. The aggressive chemical species arise from fission products generated and released during power generation. The stresses arise from the mismatch in thermal expansion of the oxide fuel pellet and that of the Zircaloy in combination with frictional forces. ${ }^{10}$ Under conditions of power changes, released fission products and stresses are present simultaneously. The resulting brittle failure involves longitudinal through-wall cladding cracks initiated at the inside tube surface. A failure with iodine as the aggressive chemical species has been reported in the literature as $\mathrm{SCC},{ }^{11,12}$ and a failure with cadmium as the aggressive species has been reported as LME. An inner surface liner of zirconium was found to be effective in preventing this type of failure. ${ }^{13}$ As discussed previously, gallium is not expected to significantly affect interactions of Zircaloy with fission products with the possible exception of cadmium that is addressed in the next section.

Gallium, if present as $\mathrm{Ga}_{2} \mathrm{O}_{3}$, could potentially intermix with the normally protective zirconium dioxide $\left(\mathrm{ZrO}_{2}\right)$ on the interior of the Zircaloy cladding. Such intermixing could be deleterious if it resulted in a lowering of the $\mathrm{ZrO}_{2}$ melting point. Although we could find no phase diagram for the $\mathrm{Ga}_{2} \mathrm{O}_{3}-\mathrm{ZrO}_{2}$ system, both oxides have relatively high melting points, and the effect of intermixing would not be expected to lower the melting point to an extent that would affect oxide performance.

One potentially serious effect of gallium on pellet-clad interaction relates to LME and is discussed in the following section.

\subsubsection{Mechanisms of Gallium Embrittlement}

Zircaloy is known to be embrittled by the presence of certain low melting heavy metals, mercury being a notable example. The effect is associated with the phenomenon termed LME (See Sect. 3.1). By this mechanism, relatively low concentrations of a liquid metal can lead to decohesion of the host metal, especially along grain boundaries, which in turn could lead to stress-assisted cracking.

It has been demonstrated experimentally that gallium can cause embrittlement of structural alloys at temperatures in the range of operating LWRs. The best known examples relate to aluminum alloys, which fail catastrophically under low stresses in the presence of gallium. Experiments relative to embrittlement of zirconium alloys by gallium have been inconclusive with respect to LWR service. Grubb et al..$^{10}$ performed constant extension rate tests 
of Zircaloy-2. At a temperature of $573 \mathrm{~K}\left(300^{\circ} \mathrm{C}\right)$ and constant extension rate of $0.85 \mu \mathrm{m} / \mathrm{s}$ $(0.002 \mathrm{in} / \mathrm{min})$, it was found that Zircaloy-2 was not embrittled when high purity gallium was added to cesium. Under these same conditions, the fission products strontium, yttrium, cadmium, as well as iodine in cesium, were found to embrittle Zircaloy-2. Recently, Cox et al ${ }^{14}$, using compact tension specimens, found that tests of $\mathrm{Zr}-2.5 \% \mathrm{Nb}$ with liquid $\mathrm{Ga}$ at $303 \mathrm{~K}\left(30^{\circ} \mathrm{C}\right)$ did not show transgranular cracking, but did show rather limited intergranular cracking. The cracking was considered to be limited by the poor wetting of zirconium by gallium.

To induce embrittlement of the Zircaloy cladding, gallium would need to be present in the form of reduced metal and in intimate contact with the metallic Zircaloy substrate. This would require transport of gallium from the fuel pellet, where it is expected to be $\mathrm{Ga}_{2} \mathrm{O}_{3}$, to the Zircaloy cladding. Potential mechanisms for such transport, although not readily predictable, were outlined in Sect. 2.3.2. A further requirement would be a break in the protective oxide $\left(\mathrm{ZrO}_{2}\right)$ overlaying the Zircaloy cladding (or zirconium liner, if one is present). Conditions at this point would be conducive to the formation of metallic gallium by reaction with zirconium (See Fig. 1.), such as

$$
2 \mathrm{Ga}_{2} \mathrm{O}_{3}(s)+3 \mathrm{Zr}(\mathrm{s})=4 \mathrm{Ga}(\mathrm{l})+3 \mathrm{ZrO}_{2}(\mathrm{~s})
$$

or

$$
2 G a_{2} O(g)+Z r(g)=4 G a(l)+\mathrm{ZrO}_{2}(s)
$$

Although the bulk concentration of gallium in the fuel is relatively low, if the above conditions were met, even small amounts of gallium could potentially be damaging because the reduction of gallium would be localized at a crack tip, where a reactive zirconium metal surface is being created continuously to drive these reactions.

Cadmium, present as a fission product in LWR fuel, has been shown experimentally to reduce the ductility of Zircaloy. Because cadmium is a relatively low melting [594 $\mathrm{K}\left(321^{\circ} \mathrm{C}\right)$ ] metal, its effect on Zircaloy is symptomatic of LME. The possibility of a synergism between the known effect of cadmium and the added presence of gallium will need to be examined. 


\subsection{WATERSIDE CORROSION}

Waterside corrosion refers to processes by which primary reactor vessel components react with cooling water. Components include fuel rods as well as stainless steel piping, the pressure vessel, and hard facings on pumps and valves. Many of these processes have been studied for more than thirty years and are well documented. ${ }^{15}$ Uniform corrosion (oxidation), nodular corrosion (accelerated corrosion), SCC, radiation transport, and crud-induced localized corrosion are examples of the types of corrosion that have been investigated. This section will address the likely effects of gallium in MOX fuel on these mechanisms and the possibility that it would introduce different mechanisms.

In general, the parameters that affect the waterside corrosion performance of Zircaloy include materials characteristics (e.g., composition, microstructure), coolant conditions (temperature, $\mathrm{pH}$, chemistry, particulates) and thermal hydraulic duty (power rating). If gallium enters the cladding, it could affect the material characteristics. Because gallium is initially present in the MOX fuel and not the clad, it starts out being isolated from the regions where corrosion reactions occur. Therefore, as has been previously stated, it must first penetrate the clad and be transported to the waterside-clad interface before it can participate. With a barrier liner for PCI protection, it would first have to penetrate the liner as well. Based on the relatively low diffusion rate of gallium, a substitutional element, at $\leq 300^{\circ} \mathrm{C}$, atomic transport through the Zircaloy clad is not expected to be a viable transport mechanism. Rather, transport of gallium to the waterside would require some form of breach (a breached fuel pin would be detected and removed) to give water access to the clad-fuel annulus.

Uniform corrosion (oxidation) and hydriding depend upon the stability of the oxide film that forms on the outside surface of the clad that is in contact with water. The very high thermodynamic stability of $\mathrm{ZrO}_{2}$ suggests that gallium would not impact the scale. Cations with an ionic radius much different from $\mathrm{Zr}^{+4}$ could produce lattice strains sufficient to crack the protective oxide; however, $\mathrm{Ga}^{+3}$ is approximately 0.8 times that of $\mathrm{Zr}^{+4}$ and so would not be expected to be highly detrimental even if it were somehow incorporated into the oxide.

Nodular corrosion is more difficult to assess. The process by which this type of accelerated corrosion occurs is not completely understood. Nodules appear to be initiated by the presence of intermetallic compounds between $\mathrm{Zr}$ and $\mathrm{Fe}$ and $\mathrm{Cr}, \mathrm{Zr}(\mathrm{Cr}, \mathrm{Fe})_{2}$. A debate remains as to whether these second-phase particles or associated solute depletion of matrix between these particles cause nodular nucleation. Most mechanisms assert that the location where production of atomic hydrogen $\left(\mathrm{H}^{\circ}\right)$ occurs in the oxide determines susceptibility to nodular formation. 
Retention of atomic hydrogen in the oxide damages the oxide and leads to accelerated corrosion, primarily in BWRs. Because mechanisms for nodule formation and oxide damage from atomic hydrogen are not well understood, it is difficult to assess the impact of gallium. However, if gallium behaves like aluminum and increases retention of hydrogen in MOX fuel, it could impact nodular corrosion if it were present in the $\mathrm{ZrO}_{2}$ protective film.

Three primary factors affect intergranular stress corrosion cracking (ISCC) of stainless steel in LWR primary water: stress, material susceptibility, and water chemistry. A fourth, radiation, has been observed to enhance ISCC by its effect on alloy sensitization and water chemistry. Because these are external to the fuel-clad assembly, gallium in MOX fuel should not affect any of these factors absent a fuel clad breach.

Given a fuel-clad breach of the size that would instigate an off-normal reactor shutdown, the global release of gallium would be extremely small in comparison with the volume of water in a 600-1200 MW LWR. Accordingly, the concentration of gallium, during the relatively short exposure time required for shutdown and after-cooling, would not be expected to affect the performance of any reactor component during the shutdown. Likewise, once the offending fuel element is removed, the residual concentration of gallium in the system would be below that which could affect reactor performance on resumption of operation. In the event of a more massive fuel-clad breach under accident conditions, there could be effects from the gallium that would add to or supersede the effects accruing from other chemical species during the accident, but little information exists by which to assess this possibility. 


\section{GALLIUM AND FUEL PERFORMANCE: CONCLUSIONS AND RECOMMENDATIONS}

The fact that the concentration of gallium in MOX fuel would be very small does not necessarily mean that effects are likely to be small to negligible. Thermochemical, kinetics, materials, and corrosion science principles must be applied to evaluate potential effects. For example, although iodine is the most deleterious fission product element in $\mathrm{PCI}$, no way exists to compare gallium with iodine because no connection is known relative to a particular corrosion mechanism. After iodine was identified as the main culprit in PCI, investigators have attempted to understand the mechanism (identified as SCC) and to determine the parameters that affect it.

In the case of gallium, it has been shown that without control of the stoichiometry of the MOX fuel it is possible for either elemental gallium or $\mathrm{Ga}_{2} \mathrm{O}_{3}$ to be present in the fuel. The temperature gradient across the fuel rod provides a potential driving force for vapor phase or solid-state transport of gallium to the fuel/clad interface, but whether it will occur is not clear. Dissolution of gallium in the fluorite structure MOX fuel would mitigate vapor phase transport, and at present, no data or information is available to permit prediction of the solid-state transport of gallium in MOX fuel. Neither dominant transport mechanisms for solid-state diffusion nor associated transport rates are known. The physical and chemical changes that will occur in the fuel during irradiation, together with the large and varying thermal gradients and cycles that will exist, further complicate any assessment of solid-state transport. Assuming that transport can occur, possible mechanisms for gallium-assisted corrosion of zirconium alloy cladding have been identified from the limited information available about the system. However, the gallium/cladding system must be experimentally evaluated to determine if the identified mechanisms do occur, how they are manifested, and what parameters impact the mechanisms and in what way. The issues raised relative to possible impacts of gallium in MOX on clad corrosion and recommended actions are as follows:

- To keep gallium as a metal oxide in as-fabricated fuel, the fuel $\mathrm{O} / \mathrm{M}$ should be at least equal to 2 .

- An understanding is needed of the oxidation state of gallium in as-fabricated and inreactor fuel under the inclusive conditions where the content of gallium in fuel remains high (i.e., near the original concentration in weapons plutonium source material), where the gallium remains concentrated in $\mathrm{PuO}_{2}$ aggregate particles in $\mathrm{UO}_{2}$, and where the fuel is fabricated at oxygen potentials such that elemental gallium (in solution) is present. Given this set of conditions, a more detailed understanding of the gallium-oxygen phase 
diagram, including any suboxide phases, would allow an understanding of whether elemental gallium (in solution) is truly stable, or whether a suboxide phase forms.

- Reactions of fission products with gallium should lead to more stable compounds than $\mathrm{Ga}_{2} \mathrm{O}_{3}$; although, it is possible that increased transport would occur. However, LME effects related to cadmium could be increased, and this sensitivity should be determined experimentally as discussed below.

- No second vapor species are known with appropriate properties with which $\mathrm{Ga}_{2} \mathrm{O}$ can form a vapor transport couple that could cause accumulation of a gallium phase at the clad surface. However, simple vaporization-condensation can occur in which the $\mathrm{Ga}_{2} \mathrm{O}$ vapor species deposits the condensed phase $\mathrm{Ga}_{2} \mathrm{O}_{3}$, particularly at fuel temperatures $>1200 \mathrm{~K}$ where $\mathrm{Ga}_{2} \mathrm{O}$ vapor pressures can reach $10^{4}-10^{5} \mathrm{~Pa}$. Higher oxygen potentials suppress the vapor pressure of $\mathrm{Ga}_{2} \mathrm{O}$ (see Fig. 1), and because oxygen potential increases with burnup, the potential for vapor transport will decrease with burnup.

- General corrosion or alloying of the cladding with gallium or gallium oxide is not a concern because general corrosion is mass limited and the quantity of gallium present in the fuel volume is low relative to the clad volume. Thus, general corrosion could only affect the innermost surface region of the cladding.

- Localized corrosion (grain boundary penetration, crack tip interactions) and liquid-metal embrittlement by gallium are possible compatibility issues that should be further investigated. Such factors as low concentrations of $\mathrm{Ga}$, the limited possibility of forming liquid $\mathrm{Ga}, \mathrm{Ga}$ mass transport kinetics, use of a barrier liner and stable surface coatings, all mitigate the probability that these localized corrosion interactions will occur. However, experimental data are needed to confirm these suppositions. These experiments should consider the effects of:

- $\quad$ physical state of gallium in prototypical fuel pellets

- $\quad$ mass transport of gallium phase (oxide)

- solid-state

- vaporization and condensation

- fuel rod temperature and temperature gradient

- concentration and distribution of gallium

- burn-up changes

- $\quad$ physical state of the pellet

- fission product interactions (e.g., cadmium) 
- cladding material composition

- cladding material coatings

- The possibility that gallium will influence water corrosion is considered remote.

Without a clad breach, gallium could only influence the sensitivity of the clad structure to stress SCC. However, the overall concentration of gallium is low, and it would have to reach the water-clad interface region by transport through the clad matrix. Some testing to demonstrate that low levels of gallium in Zircaloy cladding does not make the material subject to SCC in water should be sufficient to essentially eliminate this type of corrosion mechanism as a possibility. In the event of a breached fuel pin, a gallium compound would likely be taken into the water, but the concentration would be extremely low given the large volume of water in the primary system. Once again, some testing should be sufficient to demonstrate any possible effects on primary system components. Effects of gallium on spent fuel storage are similar to those just discussed. Temperatures are generally lower and materials other than Zircaloy and austenitic stainless steel will have to be included; however, the low concentration of gallium, especially in the absence of a failed fuel pin, makes deleterious corrosion effects highly unlikely. 


\section{REFERENCES}

1. I. A. Sheka, L. S. Chaus, and T. T. Metyureva, The Chemistry of Gallium, Elsevier, New York, New York, 1966.

2. A. Roine, Outokumpu HSC Chemistry for Windows, Outokumpu Research Oy, Kuparitie, Finland, 1994.

3. W. Von Klemm, and I. Schnick, Die Bildungswarme von Gallium I-Oxyd, Z. Anorg. Allgemeine Chemie 226, 353-358 (1936).

4. I. Barin, Thermochemical Data of Pure Substances, VCH, Germany, 1989.

5. T. L. Markin, and E. J. Mclver, "Plutonium 1965," pp. 845-57 in Proc. of the Third Intl. Conf. on Plutonium, Chapman and Hall, London 1967.

6. T. M. Besmann, and T. B. Lindemer, "Chemical Thermodynamic Representations of $<\mathrm{PuO}_{2-\mathrm{x}}>$ and $<\mathrm{U}_{1-\mathrm{z}} \mathrm{Pu}_{\mathrm{z}} \mathrm{O}_{\mathrm{w}}>$," J. Nucl. Mater. 130, 489-504 (1985).

7. H. Kleykamp, "The Chemical State of the Fission Products in Oxide Fuels," J. Nucl. Mater. 131, 221-246 (1985).

8. D. P. Butt, "Thermodynamic and Kinetics of Ga in MOX", LA-UR-97-3853, Los Alamos National Laboratory 1997.

9. T. B. Massalski, ed., Binary Alloy Phase Diagrams, Vol. 2, p. 1880, ASM International, Materials Park, Ohio, 1990.

10. W. T. Grubb, and M. H. Morgan III, "A Survey of the Chemical Environments for Activity in the Embrittlement of Zircaloy-2," pp. 145-154 in Proceedings of the Fourth International Conference: Zirconium in the Nuclear Industry, ASTM STP 681, American Society for Testing and Materials, Philadelphia, Pa., 1979.

11. H. S. Rosenbaum, Electrochemical Technology, Vol. 4, p. 153 (1966).

12. H. S. Rosenbaum, J. H. Davies, and J. Q. Pon, EURAEC Report, GEAP 5100-5105, 1966.

13. D. S. Tomalin, R. B. Adamson, and P. R. Gangloff, "Performance of Irradiated Copper and Zirconium Barrier-Modified Zircaloy Cladding Under Simulated Pellet-Cladding Interaction Conditions," Proceedings of the Fourth International Conference: Zirconium in the Nuclear Industry, pp. 122-144 in ASTM STP 681, American Society for Testing and Materials, Philadelphia, Pa., 1979.

14. B. Cox and Y. M. Wong, "Liquid Metal Embrittlement of $\mathrm{Zr}-2.5 \% \mathrm{Nb}$ Alloy," submitted to J. Nucl. Mater. 1996.

15. G. J. Theus and J. R. Weeks, eds. Proceedings of the Third International Symposium on Environmental Degradation of Materials in Nuclear Power Systems - Water Reactors, The Metallurgical Society, Inc., Warrendale, Pa., 1987. 


\section{APPENDIX \\ PHYSICAL, CHEMICAL AND NUCLEAR CHARACTERISTICS OF GALLIUM AND GALLIUM OXIDES}

\section{A.1 ELEMENTAL GALLIUM}

\section{A.1.1 PHYSICAL CHARACTERISTICS}

Gallium, a metal in Group III of the periodic table, has unusual thermal properties. It has a low melting point $\left[302.93 \mathrm{~K}\left(29.78^{\circ} \mathrm{C}\right)\right]$, it vaporizes above $2473 \mathrm{~K}\left(2200^{\circ} \mathrm{C}\right)$, has the widest difference between melting and boiling points of any element. It expands during solidification, and it is easily super-cooled in the liquid state. ${ }^{1}$ Gallium wets almost all surfaces. Some physical properties of gallium are listed in Table A.1. The boiling point is not known precisely because of the volatility of the oxide $\mathrm{Ga}_{2} \mathrm{O}$, which forms when gallium is heated in oxide vessels. $^{2}$

Table A.1. Physical properties of gallium

\begin{tabular}{lc}
\hline Property & Value \\
\hline Melting point ${ }^{\circ} \mathrm{C}$. & 29.78 \\
Boiling point ${ }^{\circ} \mathrm{C}$. & ca. 2200 \\
Density at melting point $\left(\mathrm{Mg} / \mathrm{m}^{3}\right)$ & 5.904 solid \\
& 6.95 liquid \\
Heat of fusion $(\mathrm{J} / \mathrm{g})$ & 79.8 \\
Electrical resistively $(\mathrm{m} \Omega \cdot \mathrm{m})\left(\right.$ solid at $\left.20^{\circ} \mathrm{C}\right)$ axes & a. 0.81 \\
& b. 54.3 \\
Electrical resistively $(\mathrm{m} \Omega \cdot \mathrm{m})\left(\right.$ liquid at $\left.30^{\circ} \mathrm{C}\right)$ & c. 17.4 \\
Thermal conductivity $\mathrm{W} /(\mathrm{m} \cdot \mathrm{K})\left(\right.$ solids at $\left.20^{\circ} \mathrm{C}\right)$ axes & 27.795 \\
& a. 88.4 \\
Thermal conductivity $\mathrm{W} /(\mathrm{m} \bullet \mathrm{K})\left(\right.$ liquid at $77^{\circ} \mathrm{C}$ ) & b. 16.0 \\
\hline
\end{tabular}

Source: Encyclopedia of Chemical Technology, Vol. 11, Wiley, New York, New York, 1994. 


\section{A.1.2 CHEMICAL CHARACTERISTICS}

Gallium is chemically similar to aluminum but somewhat less reactive. It forms a protective oxide surface film in air that protects it from further oxidation. Gallium is amphoteric, but it is more acidic than aluminum. This property is used to separate gallium from aluminum. Gallium, like aluminum, is normally trivalent, $\mathrm{Ga}^{+3}$. However, it may also be monovalent, $\mathrm{Ga}^{+1}$. The halogens $\mathrm{Br}, \mathrm{Cl}$, and $\mathrm{F}$ react with gallium at ambient temperature. I, $\mathrm{S}$, $\mathrm{Se}, \mathrm{Te}, \mathrm{P}, \mathrm{As}$ or $\mathrm{Sb}$ react with hot $\mathrm{Ga}^{2}$

At temperatures of $773-1273 \mathrm{~K}\left(500-1000^{\circ} \mathrm{C}\right)$ and above gallium reacts with most metals. Tungsten is one of the few metals that is unaffected by gallium.1,2 Gallium forms nine in

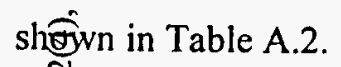

\begin{tabular}{|c|c|c|c|}
\hline & \multicolumn{3}{|c|}{ Table A.2. Gallium compounds with zirconium or plutonium } \\
\hline & Zirconium $^{*}$ & & Plutonium ${ }^{\dagger}$ \\
\hline & $\mathrm{ZrGa}_{3}$ & & $\mathrm{Pu}_{2} \mathrm{Ga}_{15}$ \\
\hline & $\mathrm{ZrGa}_{2}$ & & $\mathrm{PuGa}_{6}$ \\
\hline & $\mathrm{Zr}_{3} \mathrm{Ga}_{5}$ & & $\mathrm{PuGa}_{4}$ \\
\hline & $\mathrm{Zr}_{2} \mathrm{Ga}_{3}$ & ğ & $\mathrm{PuGa}_{3.7}$ \\
\hline & $\mathrm{ZrGa}$ & 哭 & $\mathrm{Pu}_{2} \mathrm{Ga}_{7}$ \\
\hline & $\mathrm{Zr}_{5} \mathrm{Ga}_{4}$ & z & $\mathrm{PuGa}_{3}$ \\
\hline & $\mathrm{Zr}_{3} \mathrm{Ga}_{2}$ & 范 & $\mathrm{PuGa}_{2}$ \\
\hline & $\mathrm{Zr}_{5} \mathrm{Ga}_{3}$ & $\frac{2}{2}$ & $\mathrm{Pu}_{2} \mathrm{Ga}_{3}$ \\
\hline & $\mathrm{Zr}_{2} \mathrm{Ga}$ & స్호 & $\mathrm{PuGa}$ \\
\hline & & 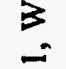 & $\mathrm{Pu}_{5} \mathrm{Ga}_{3}$ \\
\hline & & $\overline{0}$ & $\mathrm{Pu}_{3} \mathrm{Ga}$ \\
\hline
\end{tabular}


Selected chemical properties of gallium are shown in Table A.3.

Table A.3. Chemical properties of gallium

\begin{tabular}{ll}
\hline Configuration of outer electron shells & $4 \mathrm{~s}^{2} 4 \mathrm{p}^{1}$ \\
Ionic radius & $62 \mathrm{pm}^{a}$ \\
Atomic radius & $0.138 \mathrm{~nm}^{a}$ \\
Atomic number & 31 \\
Atomic mass $\left(60.1 \%{ }^{69} \mathrm{Ga}, 39.9 \%{ }^{71} \mathrm{Ga}\right)$ & $69.72 \mathrm{amu}$ \\
First ionization potential & $5.97 \mathrm{~V}^{b}$ \\
Electrode potential $\mathrm{Ga}$ (Ga ${ }^{+3}(\mathrm{aq})+.3 \mathrm{e}^{-}$ & $0.52 \mathrm{~V}^{b}$ \\
\hline
\end{tabular}

Sources: "Encyclopedia of Chemical Technology, Vol. 11, Wiley, New York, New York, 1994.

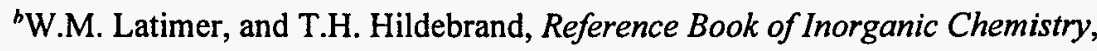
$3^{\text {rd }}$ ed., 150, Macmillan, New York, New York, 1951.

\section{A.1.3 NUCLEAR CHARACTERISTICS OF GALLIUM}

Naturally occurring gallium is made up of ${ }^{69} \mathrm{Ga}(60.1 \%)$ and ${ }^{71} \mathrm{Ga}(39.9 \%)$. The capture cross section at $0.025 \mathrm{eV}$ is 2.2 barns for ${ }^{69} \mathrm{Ga}$ and 3.7 barns for ${ }^{71} \mathrm{Ga}$. There is some capture resonance structure for both nuclides between $100 \mathrm{eV}$ and $10,000 \mathrm{eV}$ as shown in Fig. A.1. The capture resonance integral for ${ }^{69} \mathrm{Ga}$ is 18.2 barns and the capture resonance integral for ${ }^{71} \mathrm{Ga}$ is 32.2 barns.

Gallium-69 captures to ${ }^{70} \mathrm{Ga}$, which decays to germanium-70 $\left({ }^{70} \mathrm{Ge}\right)$ by beta decay with a 21.1-min half-life. Germanium-70 has a capture cross section at $0.025 \mathrm{eV}$ of 2.9 barns.

Gallium-71 captures to ${ }^{72} \mathrm{Ga}$, which decays to ${ }^{72} \mathrm{Ge}$ by beta decay with a $14.1-\mathrm{h}$ half-life. The 0.025 capture cross section of ${ }^{72} \mathrm{Ge}$ is 0.8 barns. The capture resonance integrals for ${ }^{70} \mathrm{Ge}$ and ${ }^{72} \mathrm{Ge}$ are 2.5 barnes and 0.9 barns, respectively.

The fission yields of the gallium and germanium isotopes are very low compared to other fission products for both uranium and plutonium fissions. Thus, little gallium is in nonweapons-grade fuels. 


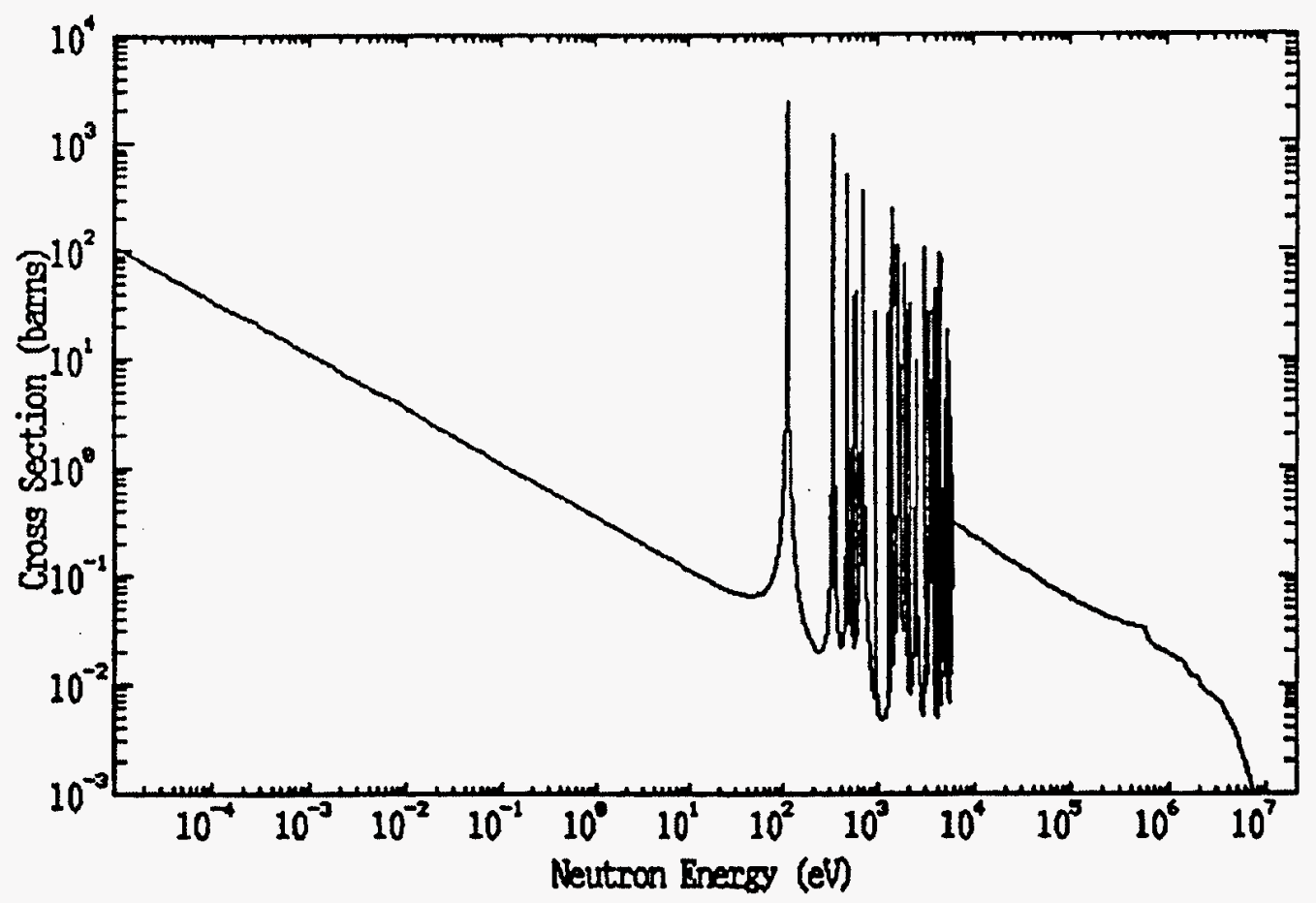

Figure A.1(a). Gallium-69 capture cross section versus energy

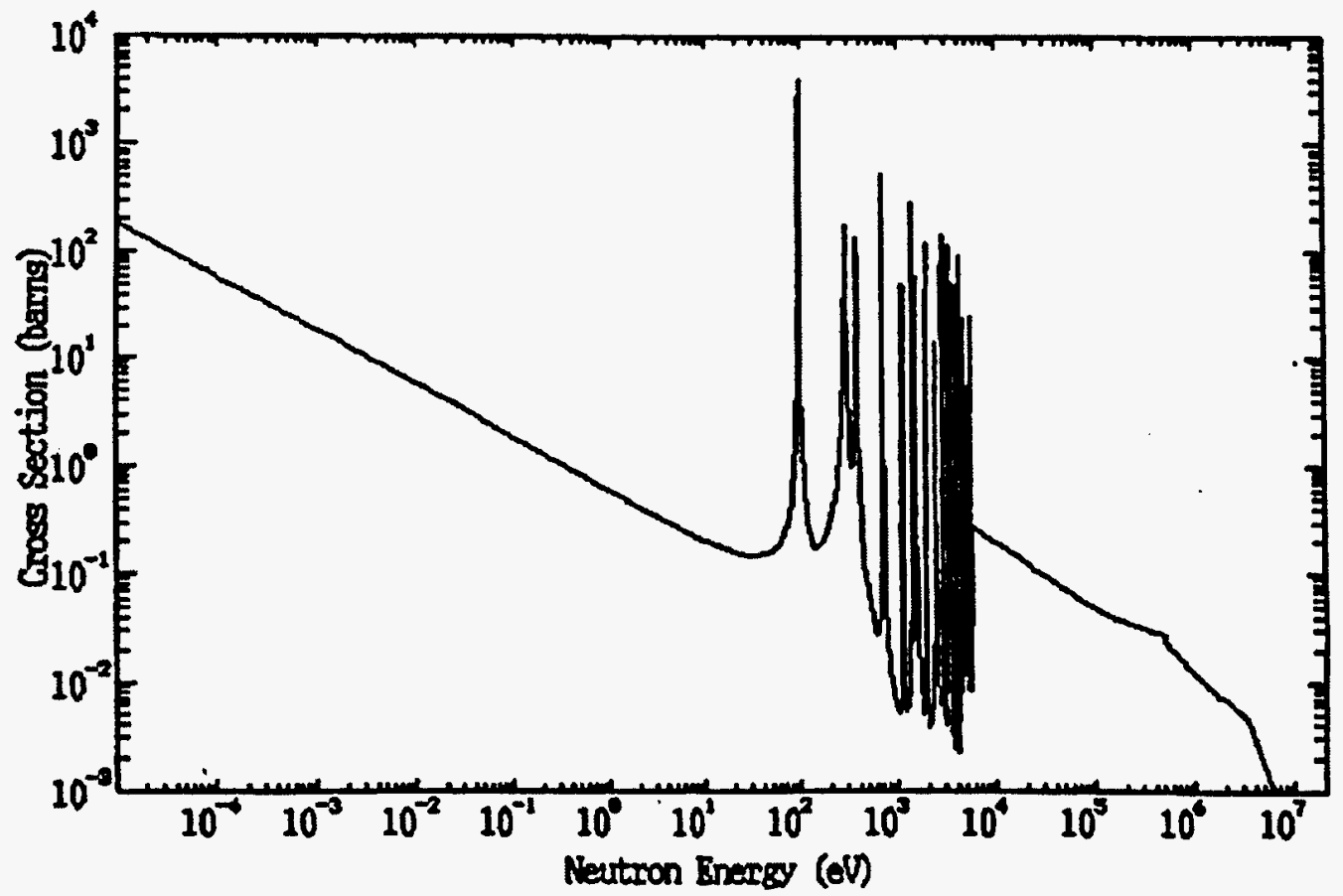

Figure A.1(b). Galium-71 capture cross section versus energy 


\section{A.2 GALLIUM OXIDES}

Gallium combines with oxygen to form the oxides $\mathrm{Ga}_{2} \mathrm{O}$ and $\mathrm{Ga}_{2} \mathrm{O}_{3}$. The oxide $\mathrm{GaO}$ has been detected in the vapor state by spectroscopy. However, gallium does not readily have a valence of +2 so this oxide, even though it has been detected, will not be considered further.

Gallium suboxide $\left(\mathrm{Ga}_{2} \mathrm{O}\right)$ forms when $\mathrm{Ga}_{2} \mathrm{O}_{3}$ is heated in a vacuum at $773 \mathrm{~K}\left(500^{\circ} \mathrm{C}\right)$ or by the reaction of $\mathrm{Ga}_{2} \mathrm{O}_{3}$ and $\mathrm{Ga} .^{1,2}$ At temperatures greater than $973 \mathrm{~K}\left(700^{\circ} \mathrm{C}\right)$ in vacuum, $\mathrm{Ga}_{2} \mathrm{O}$ decomposes into $\mathrm{Ga}_{2} \mathrm{O}_{3}$ and $\mathrm{Ga}$. Gallium suboxide exists as a dark brown solid and as a gas. Gallium suboxide is a strong reducing agent. It is oxidized to $\mathrm{Ga}_{2} \mathrm{O}_{3}$ by heating in air. ${ }^{2}$

There are five crystal modifications of $\mathrm{Ga}_{2} \mathrm{O}_{3}$. The $\beta$ (monoclinic) form is the most stable. ${ }^{1,2}$ Gallium oxide, $\mathrm{Ga}_{2} \mathrm{O}_{3}$ forms by heating gallium in air or by thermally decomposing gallium nitrate or hydroxide at $473-523 \mathrm{~K}\left(200-250^{\circ} \mathrm{C}\right){ }^{2}$ It can be reduced by heating at $\sim 873 \mathrm{~K}$ $\left(600^{\circ} \mathrm{C}\right)$ in hydrogen or carbon monoxide. Gallium oxides are insoluble in water. Gallium forms an oxyhydroxide $\mathrm{GaOOH}$ by the reaction of gallium with steam at $\sim 473 \mathrm{~K}\left(200^{\circ} \mathrm{C}\right)$.

\section{A.3 IMPURITIES}

The reaction of gallium or gallium compounds with impurities occurs in competition with other materials in the fuel and the cladding.

\section{A.3.1 HALOGEN IMPURITIES}

Fluorine reacts with all material in a fuel pin. Gallium forms the gallium fluoride $\left(\mathrm{GaF}_{3}\right)$. However other materials form more stable fluorides. The fission products $\mathrm{La}, \mathrm{Ba}$, or $\mathrm{Cs}$, in the form of either metal or oxide will react with $\mathrm{GaF}_{3}$ to form $\mathrm{LaF}_{3}, \mathrm{BaF}_{2}$, or $\mathrm{CsF}$. The following reactions are expected:

$$
\begin{aligned}
& 2 \mathrm{GaF}_{3}+\mathrm{La}_{2} \mathrm{O}_{3}-\mathrm{Ga}_{2} \mathrm{O}_{3}+2 \mathrm{LaF}_{3}, \\
& 2 \mathrm{GaF}_{3}+3 \mathrm{BaO}-\mathrm{Ga}_{2} \mathrm{O}_{3}+3 \mathrm{BaF}_{2},
\end{aligned}
$$

and

$$
2 \mathrm{GaF}_{3}+3 \mathrm{Cs}_{2} \mathrm{O} \rightarrow \mathrm{Ga}_{2} \mathrm{O}_{3}+6 \mathrm{CsF}
$$


In addition, zirconium would preferentially react with fluoride or fluorine:

$$
4 G a F_{3}+3 Z r-3 Z r F_{4}+4 G a
$$

Thus, any effect of a fluoride impurity would likely be because of its reactivity rather than because of the presence or absence of gallium.

Gallium reacts with the other halogens $\mathrm{Cl}, \mathrm{Br}$, and I to form compounds of the types $\mathrm{GaX}_{3}$ and $\mathrm{Ga}_{2} \mathrm{X}_{4}$, where $\mathrm{X}$ represents the halide. The $\mathrm{GaX}_{3}$ compounds will not be stable in the presence of the fission products $\mathrm{La}, \mathrm{Ba}$, or $\mathrm{Cs}$ or $\mathrm{Zr}$ from the cladding. The reactions would be analogous to those previously shown for the fluorides. The $\mathrm{Ga}_{2} \mathrm{X}_{4}$ compounds can be written as $\mathrm{Ga}^{+1}\left(\mathrm{Ga}^{+3} \mathrm{X}_{4}\right){ }^{1}$ No thermochemical data exist for these compounds that could be used to evaluate their stability relative to other materials. However, these halides have gallium with a valence of +1 and +3 . If the oxygen potential in the fuel is such that gallium would be in the fuel as $\mathrm{Ga}_{2} \mathrm{O}_{3}$ or a mixed oxide containing $\mathrm{Ga}^{+3}$ as is anticipated, the formation of $\mathrm{Ga}_{2} \mathrm{X}_{4}$ would require partial reduction of $\mathrm{Ga}^{+3}$ to $\mathrm{Ga}^{+1}$. It is not apparent how this could occur.

lodine and bromine are fission products. It is not likely that impurity concentrations of these elements would exceed their fission yield.

\section{A.3.2 CHALCOGENIDE IMPURITIES}

Gallium forms two types of compounds with S, Se, or Te: GaS, GaSe, or GaTe; and $\mathrm{Ga}_{2} \mathrm{~S}_{3}, \mathrm{Ga}_{2} \mathrm{Se}_{3}$, and $\mathrm{Ga}_{2} \mathrm{Te}_{3}$. The atomic arrangement in the first type of compound is such that the valence of gallium is +3 , the same valence as the second type of compound.

Fission product barium as the metal or oxide forms a more stable sulfide, selenide, and telluride than gallium. However, neither the rare earth fission products nor $\mathrm{ZrO}_{2}$ will remove the chalcogenides from gallium. Zirconium metal would react with $\mathrm{Ga}_{2} \mathrm{~S}_{3}$ to form zirconium sulfide.

\section{A.3.3 REACTIONS WITH GROUP V ELEMENTS}

Gallium reacts with $\mathrm{P}, \mathrm{As}$, or $\mathrm{Sb}$ to form $\mathrm{GaP}, \mathrm{GaAs}$, or $\mathrm{GaSb}$. Gallium arsenide is a common semiconductor material. These compounds will not form by reaction of $\mathrm{P}, \mathrm{As}$ or $\mathrm{Sb}$ with $\mathrm{Ga}_{2} \mathrm{O}_{3}$. 


\section{A.4 REFERENCES}

1. Encyclopedia of Chemical Technology, Vol. 11, Wiley, New York, New York 1994.

2. J. C. Bailar, H. J. Emeleus, R. Nyholm, and A.F. Trotman-Dickenson, eds., Comprehensive Inorganic Chemistry, 1065-1093, Pergamon Press, Oxford 1973. 
ORNL/TM-13504

Dist. Category UC-523

\section{INTERNAL DISTRIBUTION}

1. E. Beahm

2-6. T. M. Besmann

7. B. B. Bevard

8. R. A. Bradley

9. S. L. Byerly

10. E. D. Collins

11. B. S. Cowell

12. D. F. Craig

13. J. H. DeVan

14-16. J. R. DiStefano

17. E. E. Duncan

18. E. C. Fox

19. U. Gat

20. R. G. Gilliland

21. S. R. Greene

22. H. W. Hayden

23. S. A. Hodge

24. L. L. Horton

25. S. R. Martin, Jr., DOE/ORO
26. G. T. Mays

27. G. E. Michaels

28. R. N. Morris

29. R. T. Primm, III

30. D. G. O'Connor

31. L. J. Ott

32. R. R. Rahn

33. P. L. Rittenhouse

34. J. D. Sease

35. D. J. Spellman

36. C. C. Southmayd

37. K. R. Thoms

38. D. L. Williams, Jr.

39-48. D. F. Wilson

49. B. A. Worley

50. Central Research Library

51-52. ORNL Laboratory Records (OSTI)

53. ORNL Laboratory Records-RC

54. FMDP Library

\section{EXTERNAL DISTRIBUTION}

55. M. L. Adams, Armarillo National Resource Center for Plutonium, Department of Nuclear Engineering, Texas A\&M University, College Station, TX 77843-3133.

56. D. Alberstein, Los Alamos National Laboratory, P. O. Box 1663, Los Alamos, NM 87545.

57. J. F. Baker, U.S. Department of Energy, MD-1, Forrestal Building, 1000 Independence Avenue SW, Washington, DC 20585.

58. T. Barr, U.S. Department of Energy, EPG, Argonne National Laboratory, 9800 South Cass Avenue, Argonne, IL 60439.

59. F. R. Best, Armarillo National Resource Center for Plutonium, Associate Professor, Department of Nuclear Engineering, Texas A\&M University, College Station, TX 77843-3133.

60. J. J. Buksa, Los Alamos National Laboratory, P.O. Box 1663, MS-F628, Los Alamos, NM 87545.

61. D. P. Butt, Los Alamos National Laboratory, P. O. Box 1663, MS-F628, Los Alamos, NM 87545.

62. H. R. Canter, U.S. Department of Energy, MD-1, Forrestal Building, 1000 Independence Avenue SW, Washington, DC 20585.

63. A. I. Cygelman, U.S. Department of Energy, MD-3, Forrestal Building, 1000 Independence Avenue SW, Washington, DC 20585.

64. T. H. Gould, Jr., Lawrence Livermore National Laboratory, P. O. Box 808, MS-L186, Livermore, CA 94551

65. R. R. Hart, Armarillo National Resource Center for Plutonium, Associate Professor, Department of Nuclear Engineering, Texas A\&M University, College Station, TX 77843-3133.

66. H. C. Irwin, Sandia National Laboratories, P. O. Box 969, MS-9015, Livermore, CA 94551

67. S. O'Kelly, Armarillo National Resource Center for Plutonium, Associate Professor, Department of Nuclear Engineering, Texas A\&M University, College Station, TX 77843-3133. 
68. D. J. Nulton, U.S. Department of Energy, MD-4, Forrestal Building, Room 6G-050, 1000 Independence Avenue SW, Washington, DC 20585.

69. D. Peko, U.S. Department of Energy, MD-3, Forrestal Building, Room 6G-050, 1000 Independence Avenue SW, Washington, DC 20585.

70-74. P. T. Rhoads, U.S. Department of Energy, MD-3, Forrestal Building, Room 6G-050, 1000 Independence Avenue SW, Washington, DC 20585.

75. J. M. Ryskamp, Idaho National Engineering and Environmental Laboratory, P. O. Box 1625, Idaho Falls, ID 83415-3885.

76. R. H. Steele, MPR Associates, Inc., $320 \mathrm{King}$ Street, Alexandria, VA 22314-3238

77. G. B. Stevenson, U.S. Department of Energy, MD-4, Forrestal Building, Room 6G-050, 1000 Independence Avenue SW, Washington, DC 20585.

78. J. H. Thompson, U.S. Department of Energy, MD-4, Forrestal Building, Room 6G-050, 1000 Independence Avenue SW, Washington, DC 20585.

\section{WWW DISTRIBUTION}

The FMDP Web site, with a list of other relevant topical reports, is located at the following URL:

http://www.ornl.gov/etd/FMDP/fmdpproc.htm 


\section{M98054235

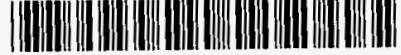

Report Number (14) ORNL/TM--13504

Publ. Date (11) 199710

Sponsor Code (18) DOE/MMD XF

UC Category (19) UC-900, DOE/ER 